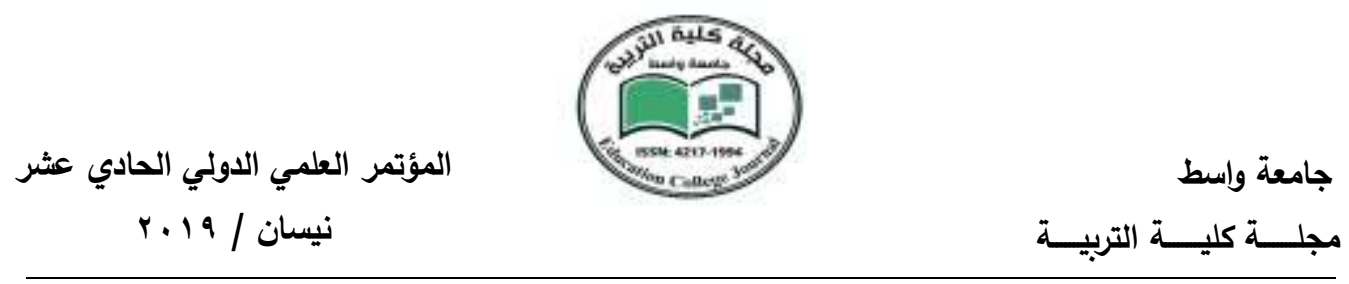

\title{
الحداثة وما بعد الحداثة في الأدب العربي والغربي
}

د. ديم محمد طيب

كلية الآداب- جامعة الموصل

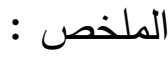

تعد الحداثة وما بعد الحداثة من أهم القضايا التي أثارت الكثير من الاهتمام والجدل ليس في

النقد الادبي الغربي فحسب، ولكن في الفكر العربي على العوم، وذلك لكونها قضية تتضمن الكثير من الالتباس والتعقيد، ولكونها أيضاً من القضايا القليلة التي استوعبتها أغلب العلوم الانسانية فهي شاملة تعبر عن المستقبل البعيد واللحاق بركب التطور المستمر الذي لا تحده نهاية.فلم تقف الحداثة وما بعد الحداثة حبيسة بيئة الثقافة الغربية بحكم منبتها ومنشئها، بل ذاعت وراحت وامتدت إلى بيئات غير بيئاتها باسم التجديد والتحديث، فأصبحت من الدفاهيم الأكثر تداولاً في الدراسات الفكرية والأدبية والنقدية العربية والغربية على نطاق واسع وتستهد كشرط لتأسيس هوية لها مقوماتها وقواعدها وخصوصية وجودها ضمن نسق ثقافي يقوم على التراث والأصالة.وقد وجدت قضية الحداثة وما بعد الحداثة صداها في أدبيات ونقديات الخطاب العربي النقدي بالاضافة إلى الأدب الغربي من خلال العديد من التعريفات التي تضمنت الحداثة وما بعد الحداثة التي اتركت جميعها في الأسس النظرية للمنهجين.إذ تعد ما بعد الحداثة حركة شمولية كما الحداثة تتشط في الفضاءات كافة السياسية والاقتصادية، والتعليمية، والاجتماعية، والفلسفية، إذ تتشظى ما بعد الحداثة إلى ما بعد حداثات مختلفة وهي أبرز ما تكون في العمارة وتخطيط الددن.ان ما بعد الحداثة تخلط بين المظاهر الاجتماعية والفكرية والثقافية وانها ردة فعل على الحداثة، كما هو متفق عليه بين الكثير من آراء الدفكرين.لقد قبلت ما بعد الحداثة النظريات الحداثة وفرضياتها واحتقت الحداثة بالعمق والمعنى، أما ما بعد الحداثة فقد نادت بعدم ثبات المعنى، وانفتاح النص وتعدد القراءات، أما ما بعد الحداثة فقد حاربت النخبة والنخبوية، وآمنت بالسطحية والمبتذل واليومي، وتغلب فيه الهامش على المركز ـ إذ بـ 

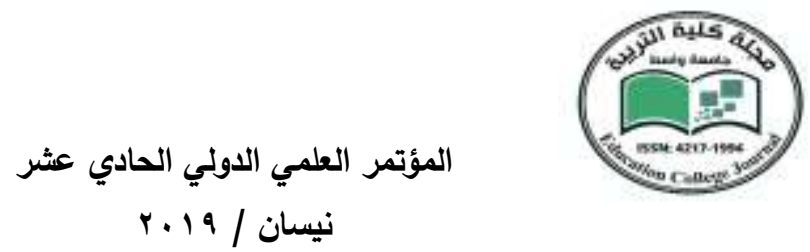

قوضت ما بعد الحداثة السلالم الهرمية، واهتمت بالأشكال التعددية، اهتماماً كبيراً.في حين أن الحداثة ثبات وشمولية أيضاً، عمل مغلق مكتمل ذا مدلول (معنى) بينما الحداثة، شكل مفتوح دال (شكل)وعليه فالحداثة وما بعد الحداثة مصطلحان او كلمتان تختصران ثقافة الإنسان المعاصر، بل قد تمتد جذورهما عبر العصور، وهما لم يأتيا من العدم بالرغم من عدمية طرحهما واختصارهما للإنسان إلى كائن لا هم له سوى المنفعة واللذة وان تعددت الثعارات والتسميات والمفردات والتبريرات لهذا تتاولنا في مبحثنا هذا الحداثة وأهم تعريفاتها وروادها ثم تطرقنا إلى ما بعد الحداثة وأهم تعريفاتها وروادها ثم انتهينا إلى خاتمة لخصت كل ما جاءت به الحداثة وما بعدها.لهذا تتاولنا في بحثنا هذا الحداثة من حيث اللغة والاصطلاح وتحديد معنى المصطلح وتتاولنا مفهوم الحداثة عند العرب والتهم الموجهة للحداثة العربية وأوهام الحداثة وبعض العناصر المحدثة في القصيدة العربية والموقف من من فئى

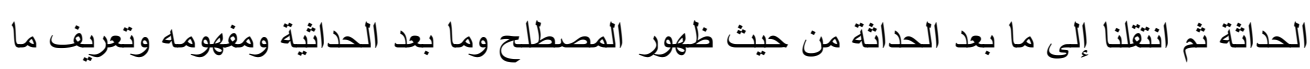
بعد الحداثة وأهم مراحل تطور مصلح ما بعد الحداثة ثم ما بعد الحداثة وما بعد البنيوية والحقنا البحث بخاتمة عرضت لأهم النتائج التي توصل اليها البحث والحق بقائمة للمصادر والمراجع.

\section{Abstract}

Modernism and postmodernism are among the most important issues that have aroused much interest and controversy not only in Western literary criticism, but in Arab thought as a whole, a matter that contains a lot of confusion and complexity, as well as a few of the few issues that most human sciences have absorbed. They are comprehensive, expressing the distant future and catching up with them. The continuous development that unites the end Modernity and postmodernity have not been confinedto. theenvironment of Western culture by virtue of their origin and origin. They have spread and spread to environments other than their environments in the name of renewal and modernization. It has become one of the most widely used concepts in the Arab and Western intellectual, literary and monetary studies on a large scale and aims as a condition for establishing its identity, Based on heritage and originality.The causes of modernity and 

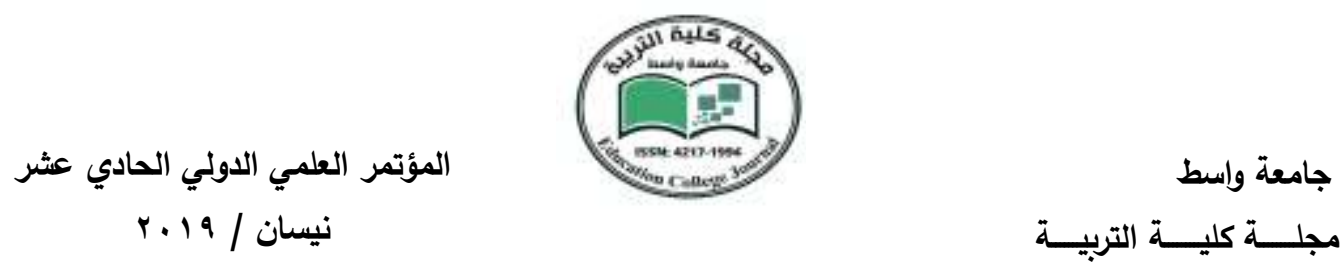

postmodernism have found resonance in the literature and criticisms of critical Arab discourse as well as Western literature. Through many definitions that included modernism and postmodernism, all of which took part in the theoretical foundations of the two approaches. The postmodernism is a movement of totalitarianism, as modernity is active in all political, economic, educational, social and philosophical spheres. The postmodernism is divided into different postmodernisms. It is the most prominent component of architecture and urban planning. Postmodernism confuses social, intellectual and cultural phenomena and it is a reaction to modernity as agreed. Many modernist thinkers have accepted the postmodernist theories of modernity and hypotheses and celebrated modernity in depth and meaning. Postmodernism has called for the lack of consistency of meaning and openness of the text and the multiplicity of readings, but postmodernity fought elite and elite and secured Superficial and tumultuous and daily and overcome the margin on the center as the postmodernism undermined the hierarchical hierarchy and paid great attention to forms of pluralism

Modernity is also a complete and complete work. It is a closed and meaningful work, while modernity is an open form. Modernism and postmodernism are terms or words that summarize the contemporary culture of man. They may extend their roots through the ages. They did not come from nothing, despite their indifference to human beings. And we have addressed the concept of modernity among the Arabs and the concerns of modern Arabism and some of the elements updated in the Arabic poem and the Stand of modernity and then move to the post-modernism in terms of the emergence of the term and post-modernist and concept and definition of post modernism and the most important stages of the evolution of the term post modernism and post-modernism and post-structural and doing a disservice research conclusion offered the most important Allantyj reached by the research and attached a list of sources and references. 
المؤتمر العلمي الاولي الحادي عثر

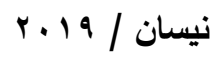

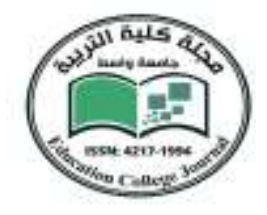

جامعة واسط

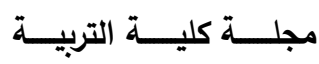

الحداثة لغة واصطلاحا :

على الرغم من تقادم العهد (بالحداثة) فان من الصعوبة بمكان محاولة ضبط مدلولات هذا

اللفظ، فالمعاجم العربية القديمة لا تقدم تفسيراً للحداثة الآّباعتبارها نقيضاً للقدم، ففي لسان العرب(1) يقال: "الحديث نقيض القديم، والحدوث نقيض القدمة، وحدث الثيء يحدثُ حدوثاً وحداثةً، وأحدثه هو، أي فهو محدث وحديث وكذلك إستحدثه ..... والحدوث كون شيء لم يكن وأحدثه الله مُحَدث. وحَدَثَ أي وقع، ومحدثات الامور ما إبتدعه أهل الأهواء من الأََّياء التي كان السلف الصالح على غيرها، وفي الحديث: "إياكم ومحدثات الامور ..... ويقول صاحب القاموس المحيط، وحدث حدوثا وحداثة نقيض قَدُمَ بضم الدال"(r)، وفي بعض مفاهيم المصطلحات : "الحديث هو القول المأثور عن

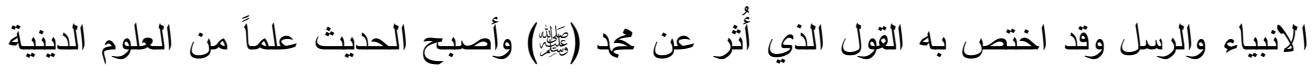

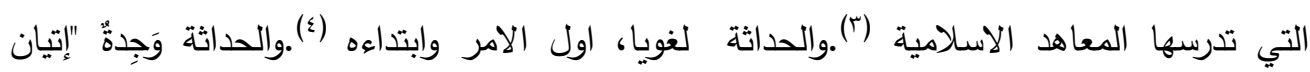
بالثيء الذي لم يؤتَ بمثلهِ من قبل، ويتحرر من أثار المحاكاة والنقل والاقتباس، واجترار القديم" (0) وقد تتمثل الحداثة في الاسلوب أو في المضمون أو في الاثنين معا، فيكون صاحبها مبدعاً، وخالف مذهب جديد مطبوع بسمته المتميزة. والحداثة "هي حركة ترمي الى التجديد ودراسة النفس الانسانية من الداخل معتمدة في ذلك على وسائل فنية جديدة"(ج)، وهي ذلك الوعي الجديد بمتغيرات الحياة والمستجدات الحضارية، والانسلاخ من أغلال الماضي، والانعتاق من هيمنة الاسلاف .. وهي ليست ظاهرة مقصورة على فئة أو طائفة أو جنس بعينه بل هي إستجابة حضارية للقفز على الثوابت وتأكيد مبدأ إستقلالية العقل الإنساني تجاه التجارب الفنية السابقة، إذ نجدها سمةٌ غالبة عند كثير من الامم، وإنّ إختلفت في منطلقاتها ومرتكزاتها الاساسية الاَّأن أَهدافها تكاد تكون واحدة( •.ويستخدم مصطلح الحداثة تاريخياً لتحديد مرحلة فنية آخذه في التلاشي، فيظهر ما يعارضها مثل (ما قبل الحداثة، الحداثة القديمة، الحداثة الجديدة، ما بعد الحداثة... الخ) (^) إنَّ تفسير دلالات المصطلح من مرحلة الى أُخرى يؤكد إستمرارية تدفق معطيات الحداثة وقوة زخمها، لأنها تتوجه نحو منطلق لا تتضمن غاية أو نهاية واضحة. 
المؤتمر العلمي الاولي الحادي عشر

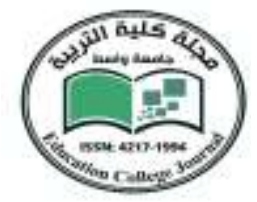

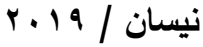

\section{جامعة واسط}

مجلـــة كليـــة التربيــة

وتبدوا التثرقة بين مصطلحي (الحديث والمعاصر)، أَمراً ملحاً في ضوء إضطراب مصطلح (الحداثة) وتقسير دلالته، واذا كان المعاصر مصطلحاً "يعني الزمن فحسب، فأن الحديث، يعني الاسلوب

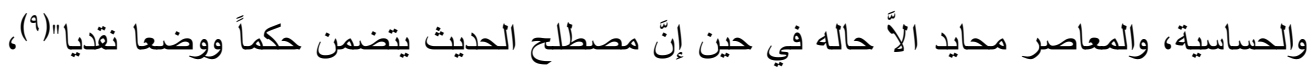

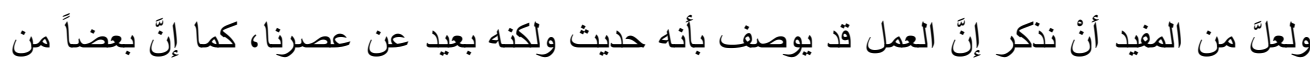
العمل المعاصر ليس حديثاً. على وفق ضوابط وحدود نقدية حاسمة للتثرقة بين هذين الدصطلحين هو الناقد المعروف (ستيفن سبندر) (·) فهو يفرق بين ما يسمى (بالانا الفوليترية) و (الانا الحديثة)، فالأولى سمة الكاتب المعاصر الواثث من عقيدته، والمبشّر بقيم ليست من نتاجه إذ يجعله يقف خارج عالم غائم يعوّزه العقل. وهو لا يشعر بان طباعُه قد كيفَّت وفق قيم المجتمع المادي، ولا يملك بالتالي

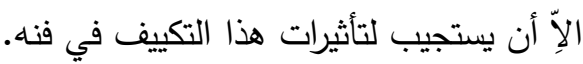

اما الانا الثانية فهي صفة الكاتب الحديث الذي يرى الحياة بشموليتها في أحوال وظروف حديثة تمكنَّ من رفضها، ويمارس معاناة لا تلين أمام قيم العصر، والحديث هو الوعي الددّرك من المعاناة والاحساس بالماضي، ويعي الحديث إثكالية الفن المعاصر بثكل جاد غير انه لا يلتقي معه في قيمه، وتتطوي (الكتابة الحديثة) على فن المراقبة الحية للحدث والثروط التي تمس الشعور، ويبدو إنَّ عالم (الظاهرة الجديدة) عند (الكاتب الحديث) يفصلنا عن عالم الماضي، وبالتالي ايضا عن الوعي التقليدي، كما إنه لا معنى في الوقت ذاته من محاولة من الرجوع الى الماضي بتجاهل الحاضر .. ان الحداثة ليست دعوة شبيهة بالعصرية فهذه الاخيرة دعوة شكلية سطحية تتعلق بطظاهر الاشياء، فلا يكون الثاعر معاصراً بمجرد أن يضيف الصاروخ أو التلفزيون ...، ان الحداثة تتفي (الوصف) من أدوات الشعر • n من

فالثعر الحديث له موقف من الكون كله لهذا كان موضوعه الوحيد وضع الانسان في هذا الوجود ؟ ولهذا أيضا كانت أدانته الوحيدة هي والرؤيا التي تغير صياغة العالم على نحو جديد"، واصبحت وظيفة الثعر هي الكثف عن عالم يظل ابداً في حاجة الى الكثف، كما يقول الثاعر الفرنسي المعاصر رينيه شار. 
المؤتمر العلمي الاولي الحادي عثر

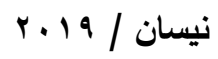

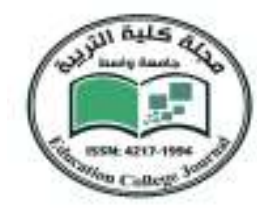

جامعة واسط

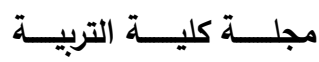

تحديا معنى المصطلح :

ان الحديث عن الحداثة ذو شجون لأنها حداثات أو "مجموعة من الحركات"('")، وليست حركة واحدة، وحداثة واحدة، وهي ليست سمة أمة أو قطر ، وإنما هي سمة العالم الجديد الذي يشهد نهضة فكرية واسعة المدى.

ولفظة (الحداثة) من المصطلحات الغامضة لجدتها وتداخل قضاياها وإختلاف أنصارها، وهي من المصطلحات الواضحة عند بعضهم أحيانا(r')، وقد وصفت بأنها مصطلح (مراوغ)(r')، ولم يشّع الإِ في السنوات الاخيرة على الرغم من وجود هذه اللفظة في المفاهيم العربية. لقد ظهرت الدعوة إلى الحداثة في أوربا في النصف الثاني من القرن التاسع عشر، وفرق الباحثون بينهما وبين (العصرية) التي بدأت ممهداتها في أوربا منذ القرن الساد عشر، واستعملت مرادفةٍ للرومانسية، وسمة لحركة جارفة غطت الحضارة الاوربية(؟)، وعدّها الماركسيون لوناً من البرجوازية الجمالية المتأخرة النابعة من الواقعية (10)...والحداثة "حركة ترمي الى التجديد، ودراسة النفس الانسانية من الداخل"(ج)، وهي "محاولة للوصول الى اسلوب فردي متميز (`') ". وكثرت تعريفاتها، ولعل بودلير أقدم من عرّفها بقوله "ما أعني بالحداثة هو العابر والهارب ونصف الفن الذي يكون نصفه الاخر هو الابدي والثابت"(1)، وهو اول من أطلاق العنان للاحلام (9'وهي "إما فن العقاب وإما السعي وراء كل ما هو مهذب ومتصنع ولا يمت الى الطبيعة بصلة، واما التشوق العازم الى التصوف والغموض، واما إنها العواطف غير المقيدة لها" (·r) وهي (ازدراء للتراث)، وضرب الصيخ التقليدية الراسخة في سير التجارب وتأملاتها" ('r)، وهي نوع من التحطيم الذاتي الخلاق(rr)، وهي "تمثل نفياً للماضي وتعلقاً بالحاضر، وخروجاً من المعتاد إلى غير المعتاد، ومن المعروف إلى غير المعروف"(rr) وهي الغاء تام للذاكرة الشعرية، ومحاولة إبتداع ما ليس له وجود قبلي عن طريق توحّد

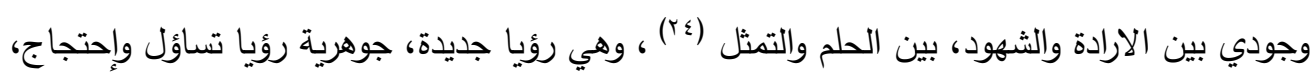
تساؤل حول الممكن وإحتجاج على السائد، 
المؤتمر العلمي الاولي الحادي عشر

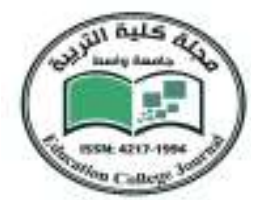

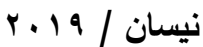

جامعة واسط

مجلـــة كليــة التربيـة

ان لحظة الحداثة هي لحظة التوتر اي التتاقض والاصطدام بين البنى السائدة في المجتمع وما

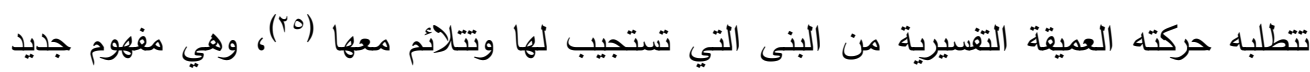
للشعر يغاير كافة المفاهيم التي عرفها التراث يغايرها مجتمعة ل لا فرادئ، بقدر ما يقارن القرن العشرون كافة ما سبقه من عصور في مجموعها، لا كل عصر على حدة، وهي عند الثعراء الجدد مفهوم حضاري اولا، إذ هو تصورٌ جديد تماما للكون صاغ نظرية لها، وهي عنده "حركية شديدة التعقيد، فهي من الناحية السلبية تدل على عالم الددن الكبيرة التي تفيض بالعقم والقبح والخطيئة عالم الشوارع المسلفتة والاضواء الصناعية والاعلانات واللافتات البشعة، ووحدة الانسان الضائع وسط

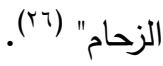

لقد وقف رامبو الموقف نفسه "فكلاهما يكره الحداثة اذا كانت تدل على التقدم المادي أو التطور العلمي، وكلاهما يتثبث بها بقدر ما تعطيه من تجارب جديدة تدفعه بخشونتها وسوادها على أن

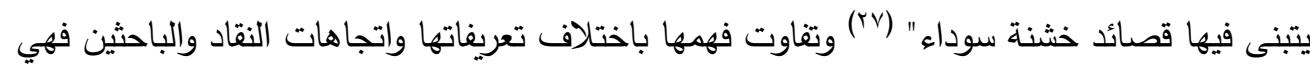
"ازالة الحدود الادبية التقليدية بين الاقطار" (「^)، وهي عند بعض الامم "ضرورة ملحة في تطور تراثها الادبي والفني، وعدتها بعض الامم نزوة عابرة" وهي "مشكلة حضارية وجمالية في أن واحد"، وهي "ظاهرة تاريخية متطورة واكبتها فترات من التأزم والتألق"، وهي "العدمية والموقف المعادي للحضارة، وتعنى كذلك التحرر من كل ما يمت الى الحضارة بصلة"، وهي اتجاه الى المعرفة التعددية الغامضة، واتجاه الى تععيل التجربة على العقل المنظم، وهي الوعي بالمستقبل، او التحليل والتأمل، و الهروب

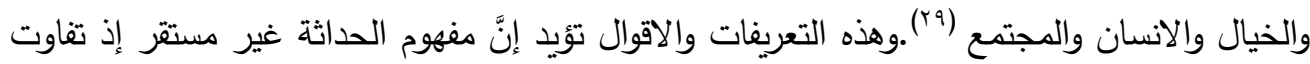
باختلاف الاتجاهات والنقاد والباحثين، وهو تفاوت يفضي الى إثكالية فهمها فهاً علمياً دقيقاً، وزاد الأمر تعقيدا إضطراب بعض العرب في فهمها مما جعّلها بعيدة عن الاذهان في كثير من الدراسات

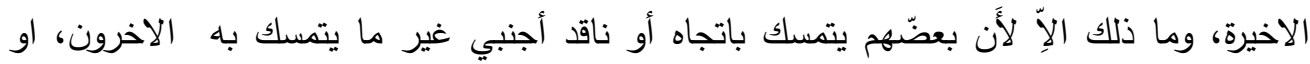

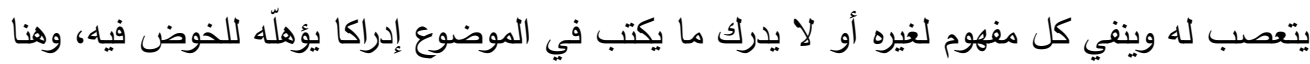
الاختلاف في تحديد المصطلح جعل بعضهم يرى إنَّ أدب الحداثة هو ما جاء به الثعوييون وغلاّة الباطنية، وما جاء به الحلوليون ودعاة التتاسخ في العصر الحديث، ودعى بعضهم الى هدم التراث 
المؤتمر العلمي الاولي الحادي عثر

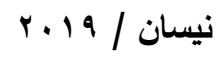

\section{جامعة واسط} مجلـــة كليـــة التربيـــة

والقيم الاجتماعية وما جاءت به الثرائع والانطلاق في عالم الرذيلة وتصوير المباذل وصرع الجنون،

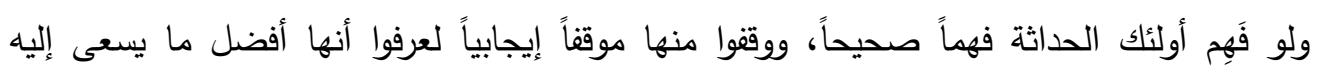

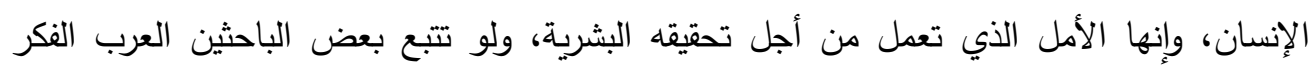
العربي لبنوا حداثة تتبع من تراثهم وواقعهم وتتطلق الى آفاق جديدة رحبة من الخير والعطاء (r.)، فالحداثة العربية المنشودة ينبغي ان تبنى بناءً يستمد أصوله من فكر الامة ويقتبس إضاءاءته من تطلعاتها، لا أن تكون شطحات يمليها الخيال الفاسد، والتصوير القاصر، والفكر الثاذ. والحداثة

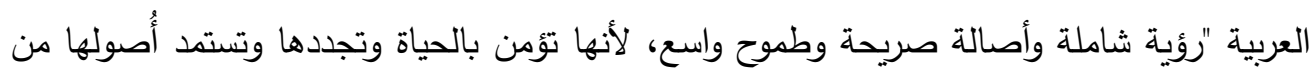

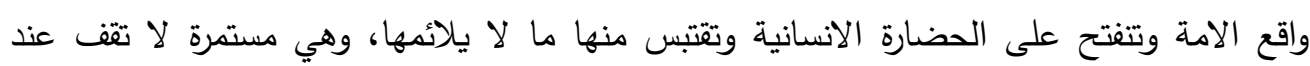

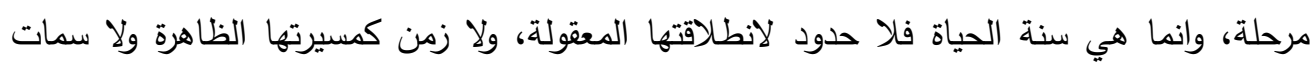

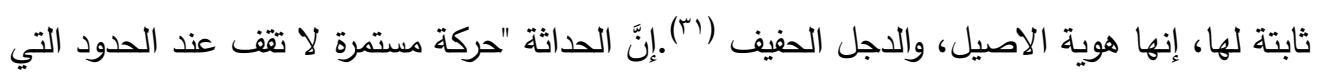

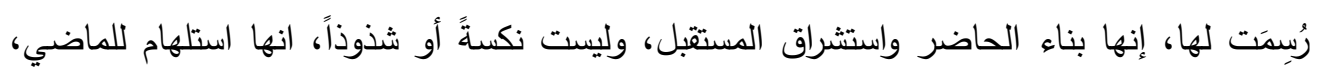
وليست نقد مسألة، إنها امتداد للتراث الحي، وليست تقاطعاً ونكرانا وتمردا عليه، إنها اكتثاف اللغة العصرية التي تستمد أصولها من اللغة الحية، وليست تحطيما لها، أو خروجا على أسسها، أنها خلق ولق التهات

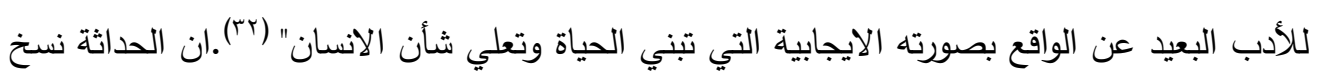

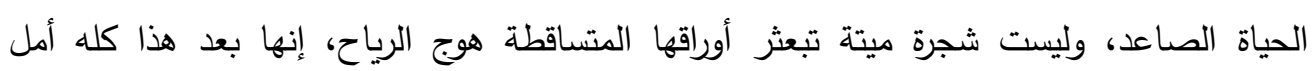
الإنسان في تقدم حياته وإزدهار حضارته في هذا العالم الذي تصطرع فيه المذاهب والاتجاهات، وإنها بناء الحاضر الزاهر وإنطلاقته الى المستقبل الزاهر هذا كله تحديد واضح للحداثة ... 
المؤتمر العلمي الاولي الحادي عثر

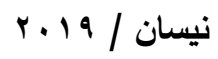

\section{جامعة واسط}

مجلـــة كليـــة التربيـــة وامبطة

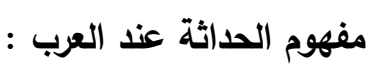

لقد شهر تاريخ الشعر العربي صراعاً بين مفاهيم قديمة واخرى حديثة منذ وقت مبكر وما موقف ابو نوأس في شعر الاقدمين، وجديد ابي تمام وابن الرومي والمتنبي وابي العلاء وغيرهم الاًّ

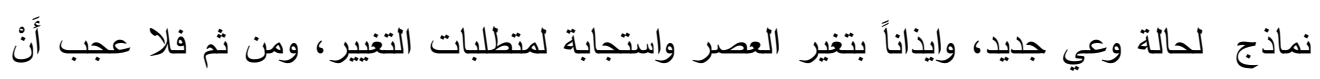

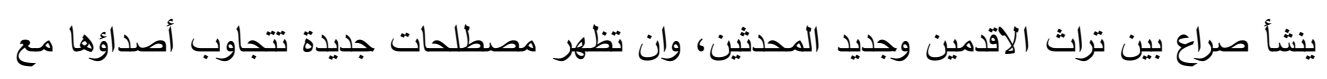

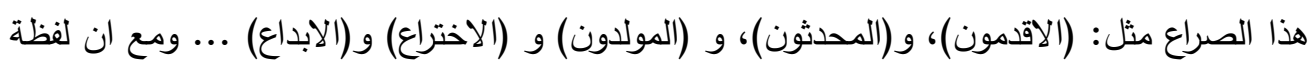

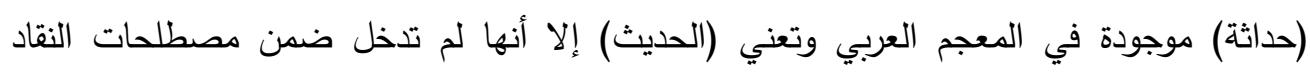

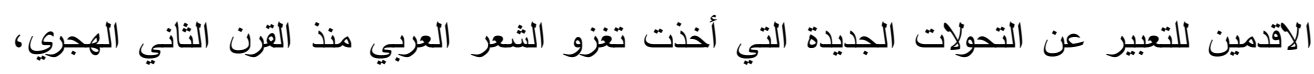

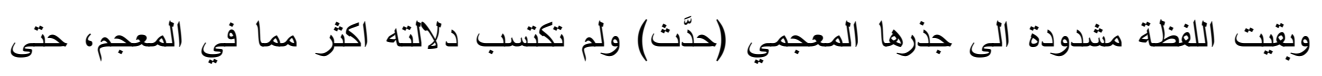
بدأت تظهر مصطلحات جديدة تقترب منها في الدلالة المعجمية وتتجاوزها في إكتساب ضلال نقدية ودلالية فرضتها الممارسات الادبية والنقدية والاطلالات من النوافذ المشروعة على الثقافة الاجنبية في

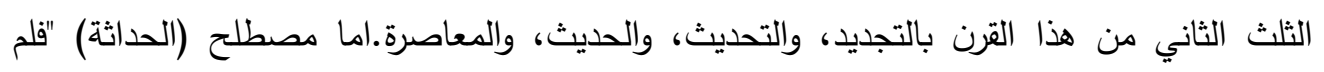
يكتسب دلالته النقدية الجديدة ويتردد صداه التقل بضلال الحركات الادبية في الغرب، وفي الكتابات النقدية الغربية الا بعد ظهور حركة الشعر الحر وثباتها في وجه التيارات الضارة لها في الخمسينات

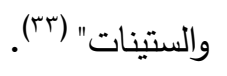

"ان الحداثة في الوضع العربي الراهن مقولة متلابسة والسبب في هذا التلابس تواتر الاتزان عند استخدام (الحداثة) لفظا ومعنى" (؟؟). فأما من جهة اللفظ، فأن كلمة الحداثة تجري مجرى الدال المتعدد الوجهات طبقُ تعدى صورة التتويه

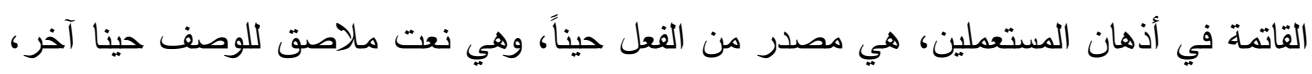
وقد تكون في سياق مغاير لفظاً متمحضا للاسمية. 
المؤتمر العلمي الاولي الحادي عشر

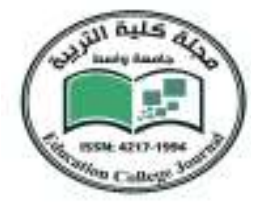

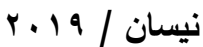

\section{جامعة واسط}

مجلـــة كليـــة التربيـــة

سواءٌ من جهة المعنى، فان (الحداثة) كثيراً ما تشحن بتضحيات تجعلها دالاً واحدة حاملا لمدلولات متعددة، وهذا التعدد بعضه من باب التتوع وبعضه من باب الاختلاف، لكن بعضه الاخر من باب التضارب حيث تتقابل فيه الدقاصد تقابلا متعاكسا.

والحاصل من كل ذلك التلابس ان لححامل (الحداثة) عندنا مفهوم يوظّف عند الاستخدام توصيف يحّمله المعنى وضده فيغذو مطية لمحامل دلالية متدرجة "يؤخذ مأخذ اللفظ المشترك ويعامل معاملة

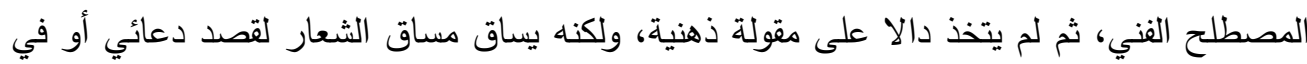

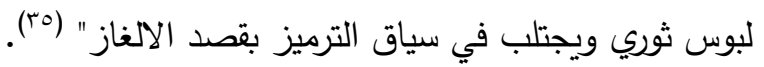

والحداثة ترتبط بمفهوم الزمن، وبديهي أن مادة (الحداثة) تتضمن "تخصيص حصول الواقعة في نقطة محدودة من محور الزمن الطبيعي، وهذا التخصيص وإن اقتضى تقدير المجال السابق والمجال اللاحق، فان مفهوم الحداثة يتضمن على وجه التعيين تقدير فضاء الزمن السابق لنقطة الحدوث اكثر

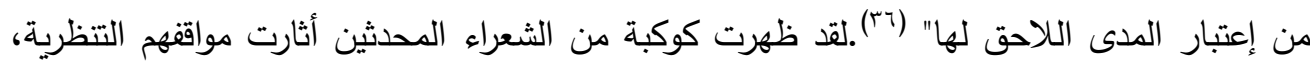
كحركة الشعر الحر جدلاً طويلاً بين النقاد، ومن هؤلاء (نازك الملائكة) حيث تراها في مقدمة ديوانها

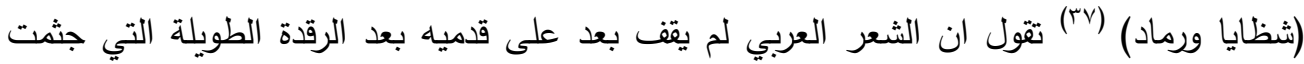

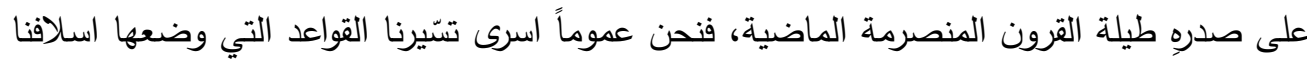
في الجاهلية وصدر الاسلام... وما زلنا نلهث في قصائدنا، ونجد عواطفنا المقيدة بسلاسل الاوزان القديمة وقرقعة الالفاظ الميتة، والذي اعتقده ان الشعر العربي يقف اليوم على حافة تطور جارف عاصف لن يبقى من الاساليب القديمة شيئا فالأوزان والقوافي والاساليب والمذاهب ستزعزع قواعدها جميعا والالفاظ ستتسع حتى تشمل افاقا جديدة واسعة في قوة التعبير والتجارب الشعرية الموضوعات ستتجه اتجاها سريعا داخل النفس بعد ان بقيت تحوم حولها من بعيد اما صلاح عبد الصبور ، فينطلق

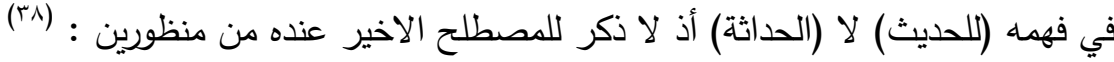
الاول: الاعراض عن مصطلح الحديث الذي يوحي بنقيضه (القديم) إذْ لا وجود لاسلوب ادبي صادر من المناقضة لان الاساليب الادبية المستخدمة تصدر في العادة عن تطور الفن الادبي نفسه من 
المؤتمر العلمي الاولي الحادي عشر

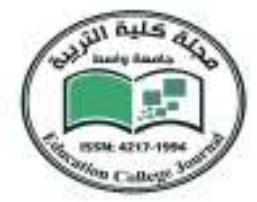

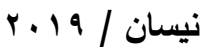

\section{جامعة واسط}

مجلـــة كليـــة التربيــة

خلال التفاعل النشط لهذه التساول عن مصدر اطلاق مصطلح (الثعر العربي الحديث) على الشعر الذي يكتب اليوم على اعتبار ان هذا المصطلح كان وراء مأزق المقارنة بينه وبين التراث العربي. اما المنظور الثاني الذي يطل منه كل (الحديث) فيتمثل بظهور شعر (التقعيلة العروضية) والذي يلمس بالثعر افاقا جديدة ويحّول عيون الثعراء الى (زوايا جديدة للرؤيا الثعرية)، وعلى هذا فالادباء (هم اصحاب لغتهم وان الشعراء هم ورثة الثعر • وان لهم الحق كل الحق في تغيير ملامحه، وتبديل قسماته وان المتنبي مثلا اعطى عطاءه ومات، فلم يعد قادر على العطاء فأورث الثعر العربي وجيله فأعطوا وماتوا، وهكذا جيلا بعد جيل حتى آلت ملكية الشعر الى هذا الجيل، فليخطوا اذن كما يشاء له وحيه وإلهامه، إن هذه الحرية التي ينادي بها صلاح عبد الصبور للانعتاق من قبضة النقد التقليدي هي علامة في طريق (الحداثة الشعرية). اما سامي مهدي فيقول(ra) : الحداثة عندي ليست مفهومات جاهزة استسقيها من هنا وهناك، بل هي حداثة روح، وحداثة نظر وحداثة تجربة، انها افق مفتوح لا تحده مفهومات قطعية ثابتة، ولا افكار احادية الجانب، ولا صراعات مؤقتة عابرة، انها تجربة حية نقاش، محورها سؤال داخلي مغلق يضع امام ذلاك الافق.وننتقل في حديثا الى ادونيس الذي أصبح أبرز أعلام الحداثة في هذا العصر، فنرى ان مفهوم الحداثة عنده يأخذ طابعاً شموليا يتتاول كل موضوعات الحياة الراهنة والماضية سواء اكانت حداثة علمية أم حداثة التغييرات الاقتصادية والاجتماعية والسياسية، أم حداثة فنية... ومفهوم الحداثة على هذا النحو يضع التراث كله في اشكاليه معقدة مع البنية الحديثة التي تؤسس وجودها لا على

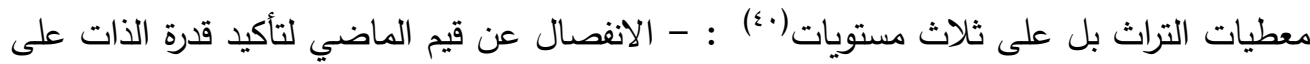
الابداع الجديد واسقاط التراث من الذاكرة التاريخية إذ تقفد عناصره ومكوناته صفة الحياة، وانتقاد الرموز الصالحة من التراث، وهذه تحتاج الى مهارة خاصة قد لا تتوفر الا لقلة من المبدعين : فهو يرى بأن نجعل الزمان أُفقاً لنا : لا نعود اسرى الماضي، بل العكس يصبح الماضي اسيرنا، ولا يعود الحاضر سيدا علينا، بل على العكس يصبح تابعا لفعاليتنا، ولا تعود جزءا من المستقبل، بل يصبح المستقبل الثكل الزمني لابداعنا، ومع هذا فأن شعر ادونيس مثقل بالتراث الذي يمتزج بالعمل الفني فيكون لحمة فنية ضمن شبكة معقدة من الرموز الذي يحار في تقسير معانيها الكثيرون. 
المؤتمر العلمي الاولي الحادي عشر

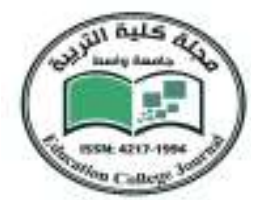

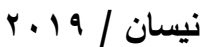

\section{جامعة واسط}

مجلـــة كليـــة التربيــة فيطة

وتعني (الحداثة الثعرية) عند ادونيس تساؤلا حادا يفجّر آفاق اللغة الشعرية ويفتح دروبا وافاقا تجريبية جديدة في فضاء الممارسة الابداعية وهذا لا يتحقق عنده الا اذا وقع ضمن اطار النظرة الثخصية الفردية للإنسان والكون، ويتشابك مع هذا المفهوم مع اربعة عناصر اساسية في تحديد المفهوم الكلي (للحداثة الشعرية) وهي : الشعر، الشكل الشعري، اللغة، والثاعر .

فالشعر ، رؤيا، والرؤيا قفزة خارج المفهومات السائدة، وهي أذن تغيير في نظام الاشياء، وفي نظام النظر اليها(")، هكذا يبدوا الثعر اول من يبدو تمردا على الاشكال والطرق الثعرية القديمة. فهو تجاوزاً وتخط يسايران تخطي عصرنا الحاضر للعصور المادية.اما الثكل ، فهو الاطار الذي يضم هذه التجربة الجديدة في الرؤيا للحياة التي تستلزم تجاوز للشروط الثكلية، ومزيدا من الحرية لاشكال

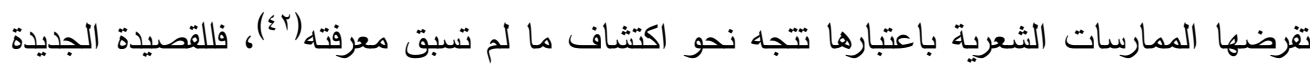
نظامها الخاص، فثكل القصيدة الجديدة هو وحدتها العضوية، هو واقعيتها الفردية التي لا يمكن تفكيكها قبل ان تكون ايقاعا أو وزنا.وتأتي لغة القصيدة الحديثة بأبعاد لغوية غير مألوفة تتتاسب مع ما تطرحه القصيدة الحديثة من تساؤلات ورؤى لم تكن معروفة من قبل (فالثعر الجديد فن يجعل اللغة تقول ما لم تتعود ان تقوله، ويصبح الثعر ثورة على اللغة)، ومن هذا الففهوم تفقد اللغة حياتها وتتلاشى المسافة بينهما وبين التجربة الابداعية فتدخل في نسيج التجربة الفنية وتتصهر معها وتخرج من هذا الصهر دلالات وايحاءات وطاقات تعبيرية جديدة.

واما الثاعر:- فارس النص ومبدع التجربة، فيقتضي عنده ان يتجاوز القيم الثابتة في التراث الشعري القديم بخاصة والتراث الثقافي بوجه عام حتى يكون قادرا على ان (يبدع شعرا في مستوى

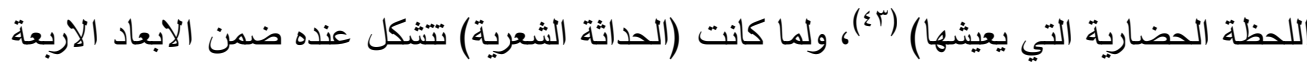
السابقة، فيقضي حتما ان تكون جميعا ضمن منظور التعارض مع التراث فلا حداثة الا بفكرة التجاوز والتخطي والانفصال وهدم القيم السابقة، ولا ابداع الا بنبذ القيم التقليدية في النظرة الى الحياة

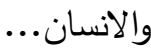


المؤتمر العلمي الاولي الحادي عثر

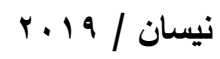

\section{جامعة واسط}

مجلـــة كليـــة التربيـــة

اما يوسف الخال (مؤسس كل شعر اللبنانية) (๕๕) فيرى ان (الحداثة الشعرية) ابداع وخروج عن

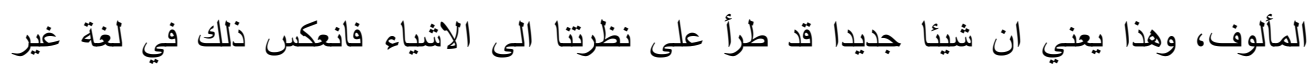
معروفة، وتفترض الحداثة إنبثاق شخصية شعرية ذات تجربة حديثة تتشكل في الثكل والمضمون فهي ليست زياً يمكن ارتداؤه أو شكلاً يمكن اقتباسه، انها في الدرجة الاولى موقف من الحياة في رؤيا

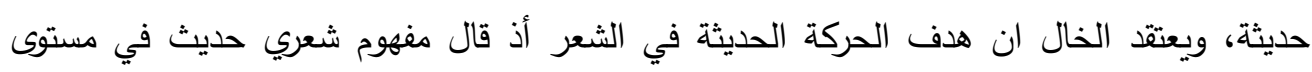
العصر الذي نحت منه الا الى الادب العببي، وما الحرية التي يتحدث عنها والتي اتخذها الثاعر العربي الحديث لنفسه الا ضرورة اقتضاها هذا المفهوم، فهي مظهر خارجي لحقيقة داخلية، وهذا الدفهوم الجديد يتلخص في، ان الشعر تجربة شخصية ينقلها الثاعر الى الاخرين بشكل فني يناسبها" (؛)، ويبدو ان الحرية عند الكاتب تعني امرين: الدفاع عن (قصيدة النثر)، (وحدود اللغة الثعرية)... ففيما يتعلق بالأمر الاول، نجد ان الخال ورفاقه دأبوا على نشر قصائد تخلو من الوزن واعتبرها

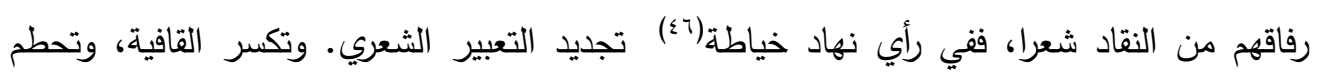
تفعيلات الخليل، ابتغاء الوصول الى أرقى صورة وأصفى معاينة.اما الامر الثاني وهو (حدود اللغة

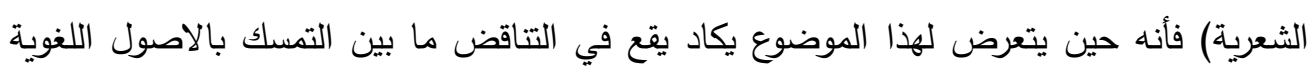

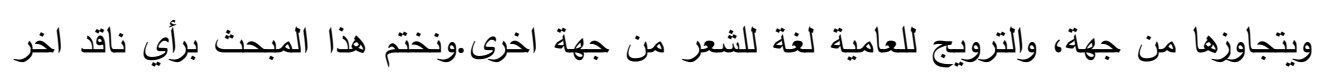

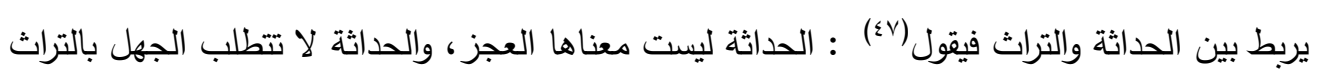
كما ان الحداثة لا تدعو الى الجهل بالتراث.

\section{التهم الموجه للحداثة العربية}

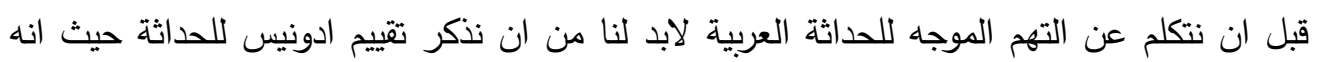

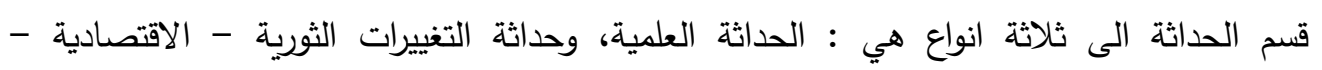
الاجتماعية - السياسية واخيرا الحداثة الفنية

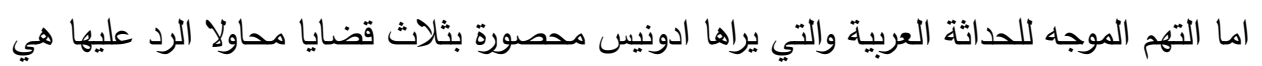

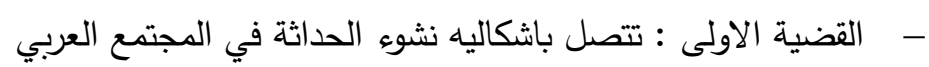

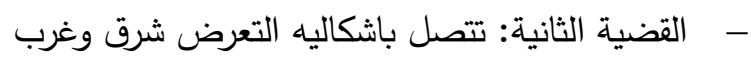
- - القضية الثالثة : تتصل بمعنى الحداثة العربية الثعرية وبخصوصيتها. 
المؤتمر العلمي الاولي الحادي عشر

فالنسبة للقضية الاولى يلاحظ ان المحدث الثعري العبي نثأ كخروج على محاكاة النموذج القديم أي

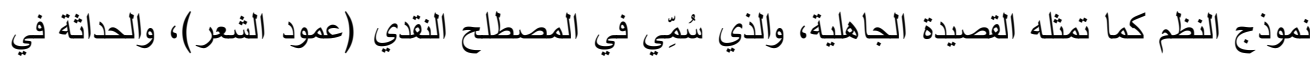

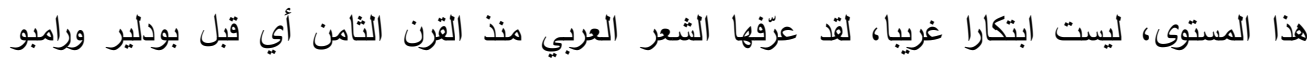

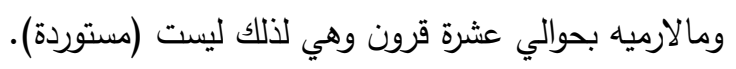

اما فيما يتعلق بالقضية الثانية فيلاحظ ان العرب بالقطع العثماني قد انفصلوا عن الابداع الحضاري،

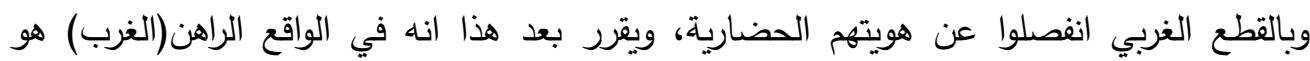

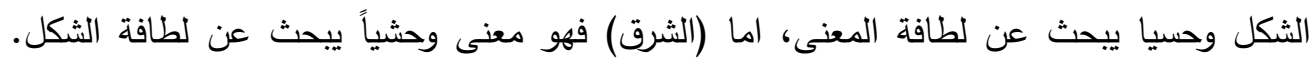

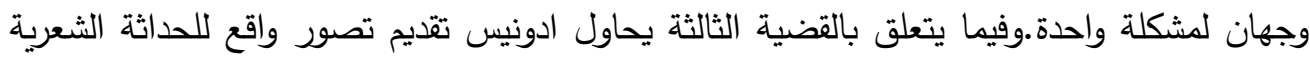

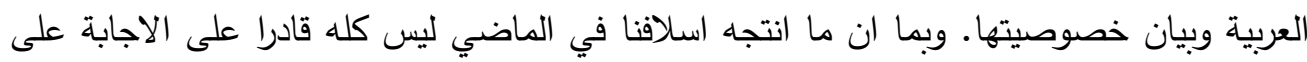
مشكلاتنا الراهنة وبما ان في الغرب ابداعات تجيبنا عن كثير من مشكلاتتا، فان ما ينقله الينا ليس اليس الئا كله خاليا من الحق. فالحداثة بالتالي ليست غربية اكثر فئر ماعا هي عربية. هكذا تتبثق الحداثة العربية من قديم عربي هي في الوقت نفسه في تعارض معه. فأن تكون شاعرا

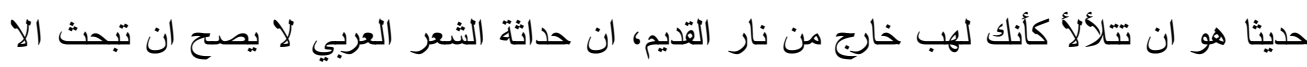

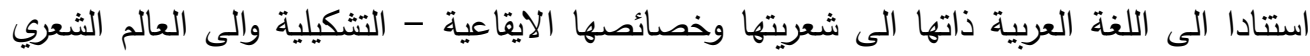
الذي تتنج عنها وعبقريتها الخاصة في هذا كله. والخلاصه ان الحداثة انتقال نحو سمة - رؤية ما، حساسية ما، تشكيل ما، ليست الغاية وليست في

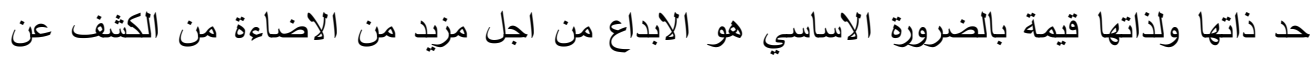

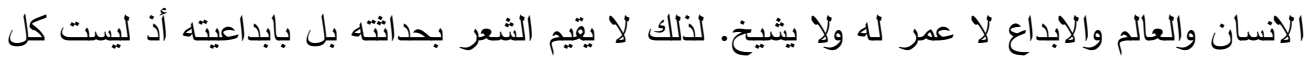

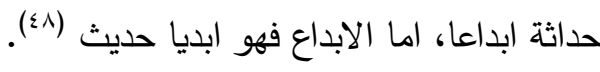


المؤتمر العلمي الاولي الحادي عثر

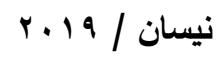

\section{جامعة واسط}

مجلـــة كليـــة التربيـــة

اوهام الحداثة : (1) - n

تداولت بعض الاوساط الشعرية العربية ما سمي ب (اوهام الحداثة) محاولة منهم لإخراج الحداثة عن مدارها، وقد حاول ادونيس تبديد هذه الاوهام والذي حددها بخمسة اوهام وهي : الزمنية المغايرة، المماثلة، التشكيل النثري، الاستخدام المضموني.

ا. وهم الزمنية: (حيث انه يميل الى ربط الحداثة بالعصر، بالراهن من الوقت من حيث انه

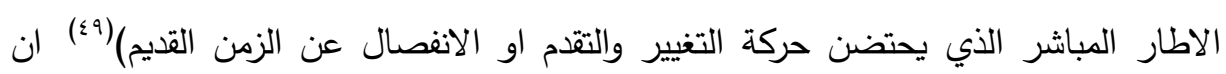
كثير من الحداثة (ما يكون ضد الزمن لحظة راهنة ومعنى ذلك ان ثمة شعرا كتب في زمن ماضي لا يزال مع ذلك حديثا، فالثعر لا يكتسب حداثته بالضرورة من مجرد زمنيته، وانما

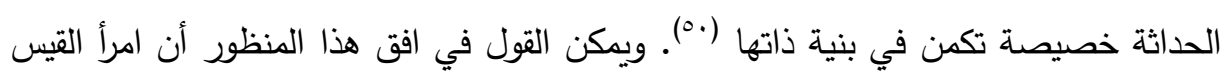
مثلا في كثير من شعره. اكثر حداثة من شوقي في شعره كله.

r. وهم المغايرة : - ويذهب اصحاب الى أن (التغاير مع القديم موضوعات واشكالا هو الحداثة او الدليل عليها)، ويذهب ادونيس نفسه على ان الحداثة هي (التغاير الخروج عن النمطية،

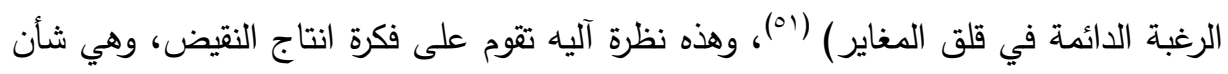

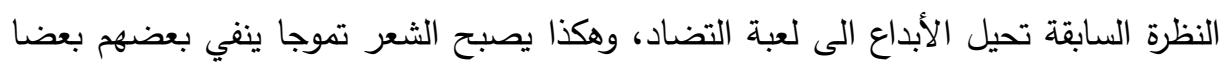
مما يبطل معنى الثعر والابداع (or). r. وهم المماثلة : ويعني عند ادونيس (ان الغرب مصدر الحداثة اليوم بمستوياتها المادية والفكرية

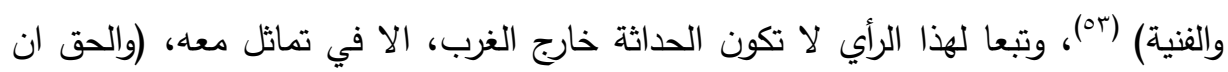
شعر المماثلة مع الخارج المحتذى ليس الا الوجه الاكثر اغراقا في ضياع الذات لشعر الماثلة

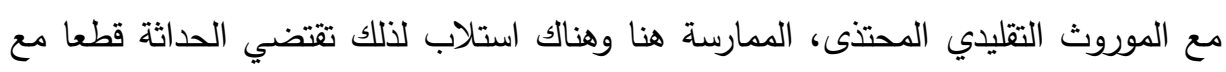

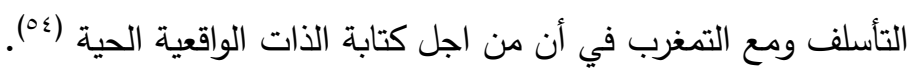
ع. ـوهم التشكيل النثري ووهم الاستحداث المضموني(00). فالأول هو الاعتقاد بأن الكتابة بالنشر (انما هي ذروة الحداثة)، والذهاب الى القول بنفي الوزن، والنظر اليه "كرمز قديم يناقض 
المؤتمر العلمي الاولي الحادي عثر

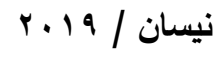

جامعة واسط

مجلــــة كليــــة التربيــــة

الحديث" (10)، فوهم النثر استغراق في المغايرة المماثلة، ووهم المضمون استغراق في الزمنية،

فمن الناحية الأولى يرى بعض الذين يمارسون كتابة الشعر نثرا، وان كتابة النثر هي تماثل

كامل مع الكتابة الشعرية العربية انما هي قمة الحداثة، ويزعم بعضهم انسياقا وراءوهماستحداث

المضمون (ان كل نص شعري يتتاول اتجاهات العصر وقضاياه وهو بالضرورة نص حديث،

وهذا زعم متهافت).وخلاصة القول ان حداثة النص الشعري ليست في مجرد زمنيته او مجرد

تشكيليته فانها كذلك ليست في مجرد مضمونيته.وبعد ان يبدد ادونيس اوهام الحداثة يتكلم

الثاعر احمد عبد المعطي حجازي عن اوهام الحداثة الشعرية، فقد حدد الثاعر حجازي هذه

الاوهام في ثلاث محاور هي ا ـ الوزن المعجم ب. الاستعارة.

الوهم الاول (ov): الوزن : حيث يرى "ان كثيرا من الناس يظنون ان الفارق بين القصيدة التقليديةوالقصيدة الجديدة هو الوزن، فالجديدة لا تكون كذلك الا بمدى خروجها وتمردها على الاوزان والقافية، وهذا وهم عنده، وحين طرقت (القصيدة الجديدة) العروض والقافية لم تطرحه الا مضطرة لانها كانت تريد ان تكون بمنأى عن اسرار اللغة القديمة وهذا يختلف عن اسقاط الوزن كأساس للتجديد" (01)

اما الوهم الثاني فهو القول بأن (للقصيدة الجديدة) معجما شعريا خاصا بها والحقيقة (ان الالفاظ وحدها لا تضع القصيدة، ولكنها اللغة والعلاقات التي تتظم هذه اللغة في السياق الشعري العام، ضمن نظام خاص يكسب اللغة خصوصيتها، ومن الضروري ان تكون مفردات هذه اللغة قد "تحققت

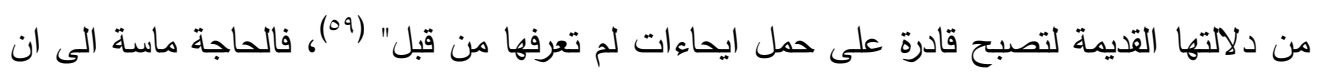
نرد الالفاظ الى منابعها الاولى الى حالة الخلق والتكوين قبل ان ترتدي معانيها المزيفة.

الوهم الثالث: فمتعلق بالفكرة الشائعة عند الثعراء الجدد من ان لغة القصيدة ليست الا الصورة، وان الصورة هي الاستعارة وكلما كانت الاستعارة تتسم بالغرابة كانت القصيدة حديثة، وهذا خلاف الحقيقة لأن الاستعارة هي اداة من ادوات الشعر ولا مراء في ان القصيدة تحتاج الى استعارة جديدة وان هذه الجدة لا تقاس بمدى غرابتها وانما بمدى اسهامها في تشكيل الرؤيا الجديدة. 
المؤتمر العلمي الاولي الحادي عثر

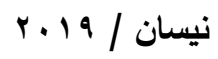

جامعة واسط

مجلـــة كليـــة التربيـــة

بعض العناصر المحدثة في القصيدة :

تقدم الحداثة نفسها على انها اشكاليه تستعصي على الحل من المنظور النظري، ولكنها تعود في النهاية الى ابداعات تطبيقية خطية وتتجلى هذه الاشكالية في ان الحداثة تتاضل على الدوام من غير ان تتوخى الانتصار لأنه لا يمثل هاجسا لها، بل عليها ان تتاضل في نفسها كما انها لا تعني في

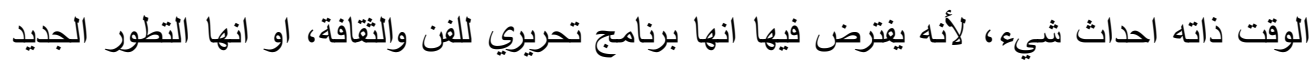
للحياة ذاتها، "ويشها التجريب المستمر في الفن والادب على نحو الادراك الواعي للتنفيذ عند الفنانين

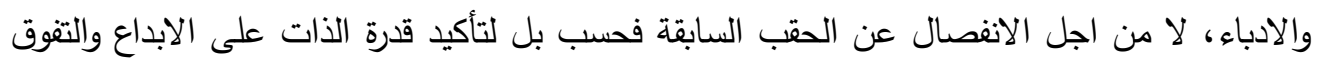
في ظل ايقاعات الزمن المتلاحقة والتطور الدذهل في النحو المعرفي، والتغييرات السياسية والاجتماعية والاقتصادية والاستجابة الايجابية لمظاهر التغيير عند مختلف الثرائح الاجتماعية، ولذا انعكست اثار هذا التجريب من اعمال الكتاب والفنانين من خلال الحركات الفنية المعروفة بالرمزية والسوريالية والطبيعية والراوية والتصويرية والمستقبلية مشفوعة ببيانات يصدرها الكتاب بين وقت وآخر توضح ابعاد اعمالهم الفنية" (·7).

اما العناصر المحدثة في القصيدة العربية المعاصرة فهي لا تلتمس موضوعاتها "فالموضوعات وحدها لا تخلق (الحداثة الثعرية) فقد تكون الموضوعات حديثة ولكن اسلوب تتاولها يتم عبر الانساق التقليدية وانما تلتمس في الادوات. الموقف من الدداثة :

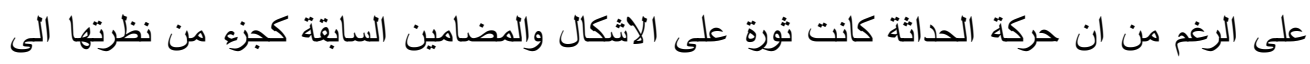
الحياة والعالم. فقد ادت الى بروز اعمال خصبة في الادب والفنون وفتحت افاقا ودروب جديدة امامها،

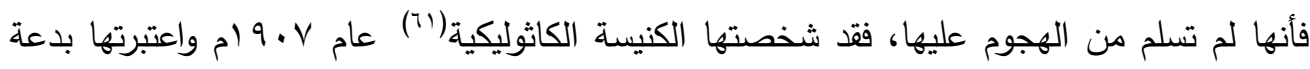

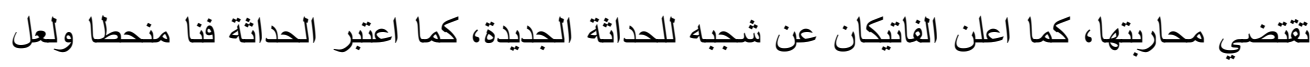
الادب الالماني نفسه قد مهر لمثل هذا الرفض فقد اصيب الادب بالتخدمة والغثيان من مصطلح

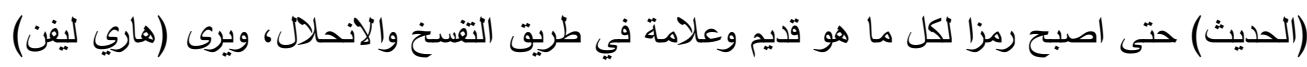

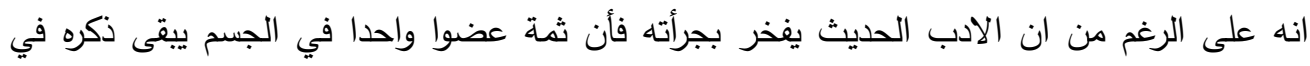


المؤتمر العلمي الاولي الحادي عشر

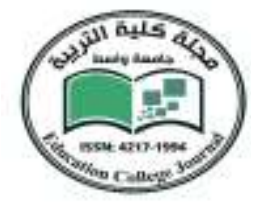

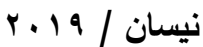

\section{جامعة واسط}

مجلـــة كليـــة التربيـــة

الغالب محظورا الا وهو العقل، ولعل ما يؤخذ على المحثين انهم كانوا مغرمين بأفكارهم الشخصية، بل اسوء من ذلك انهم يطلبون من عقول قرائهم مطالب حادة، ويأخذ الناقد الماركس (لوكاتش) على التى التهين الحداثة موقفها السلبي من الانسان والتاريخ كالإنسان في اعمال كبار المحدثين ليس اجتماعيا بطبعة،

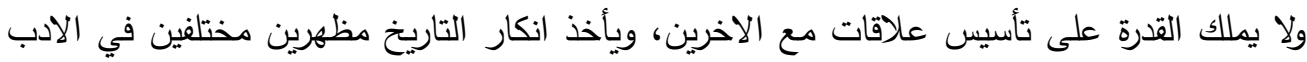
الحديث، فالأول يتمثل في اقتصار البطل بثكل جاد على حدود تجاربه الإنى الذاتية ويتجسد المظهر الثاني

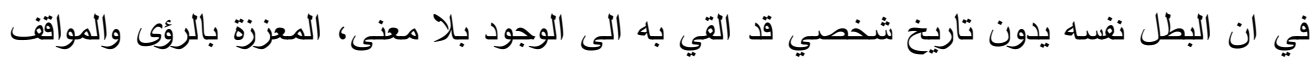
التي تكثف استار الواقع وحجبه، فتعرى زيفه ومتتاقضاته وتغوص في اعماق النفس فتعري الانسان

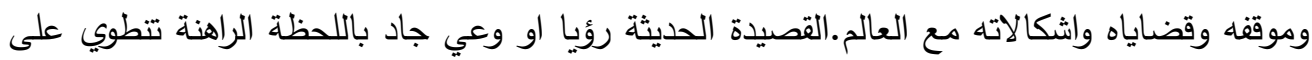
سلوك فكري يصدر عن ايمان (الأنا) مجتمعة التغير من خلال جدلية الصراع بين (الأنا) وتعاليها

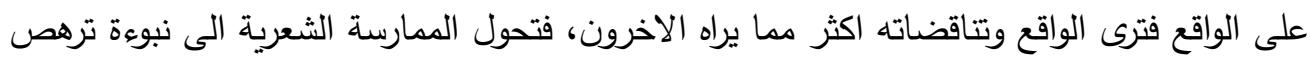
بنذر التغير ويتحول الثاعر الى ان يكون بين عصره يستمد وحيه من اعماق الحس فئس فتشكل رؤياه

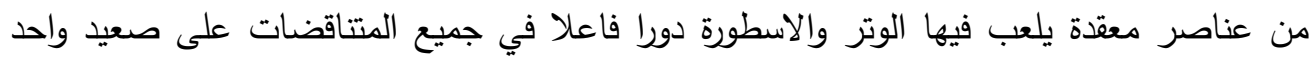

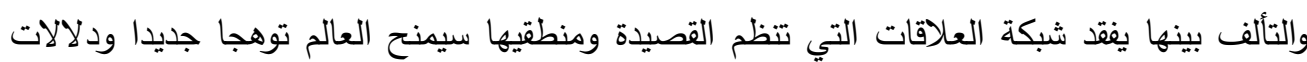
جديدة (Tr)، ومن المرتكزات الاساسية المحدثة في الخطاب الثعري المعاصر (كسره لنمطية اللغة واستخدامه لغة سرية جديدة تتمدد كل القوالب التي لاكتها الالسنة حتى اصبحت فارغة من مضامينها الحقيقية والثاعر حين يتمرد على اللغة او بعبارة ادق يتمرد على نمطية التغيير يعبر خلق اللغة من

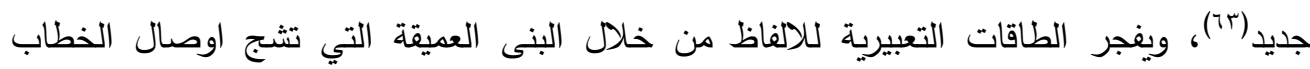

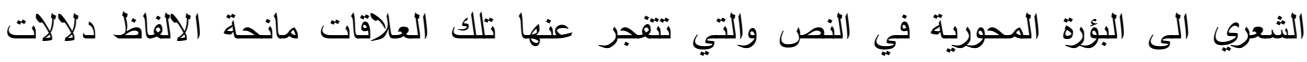
وايحاءات جديدة واللغة الشعرية احساس ووعي مقصود لذاته انها تغرض نفسها باعتبارها اداة فوق

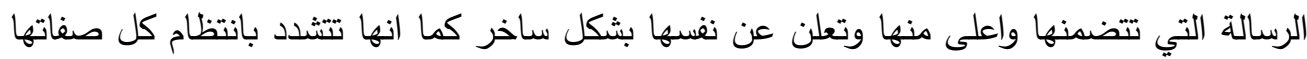
اللغوية، ومن ثم فلا تصح الالفاظ مجرد وسائل لنقل الافكار ، بل اشياء مطلوبة لذواتها، وكيانات مادية مستقلة بنفسها وعلى هذا تتحول الكلمات من دوال الى مدلولات ولعل ما يميز اللغة الشعريالحديثة عن غيرها (اتسامها بالطابع المحسوس للبنية التركيبية والاحساس بالمظاهر الصوتية والدلالية للفظ...(1) 


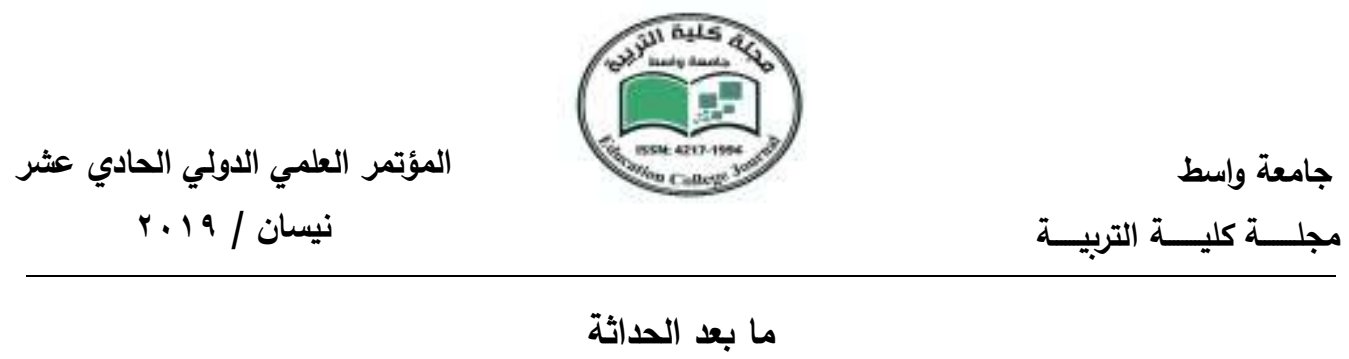

باية المصطلح :

يعتبر مصطلح ما بعد الحداثة من المصطلحات التي شاعت وسادت منذ الخمسينات من القرن الماضي ، ولم يهتد احد بعد الى تحديد مصدره ، فهناك من يعيد المفردة الى المؤرخ البريطاني ارنولد تويني عام ع 190 ، وهناك من يربطها بالثاعر والناقد الامريكي تثارلس اولسون في الخمسينات ، وهناك من يحيلهما الى ناقد الثقافة ليزلي فيدلر ويحدد زمانها بعام 1970 ، على ان البحث عن اصول المفردة افضى الى اكتثاف استخدامها قبل هذه التواريخ بكثير ، كما في استخدام جون واتكنز تثابمان لهصطلح ((الرسم ما بعد الحداثي)) ، في عام • أم ، وظهور مصطلح ما بعد الحداثة

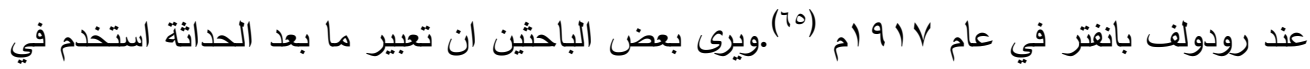
الثلاثينات من القرن العشرين في نص كتبه الاسباني فردركلودي اونيس ، الا ان الاستخدام الاول لهذا المصطلح بصورة منهجية كان في حقل الدراسات النقدية في امريكا : اي في كتابات كل من

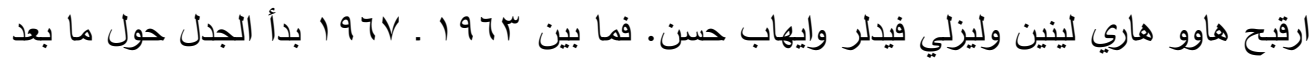
الحداثة يعلن عن نفسه في الادب والفنون والعمارة ، فنشر ليوناردماير دراسته نهاية عصر النهضة

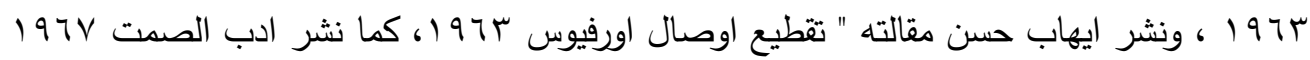

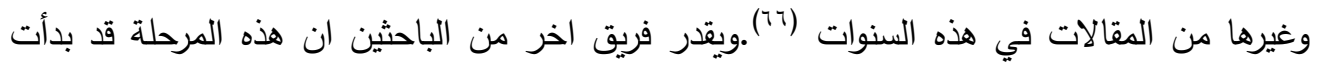
تاريخيا منذ عام 1971 وهي المرحلة التي عرفت بثورة الطلاب في مختلف عواصم العالم وعلى ترك خلاف ذلك يرى الفريق الاخر ان مرحلة ما بعد الحداثة قد بدأت مع سقوط جدار برلين تعبيرا عن

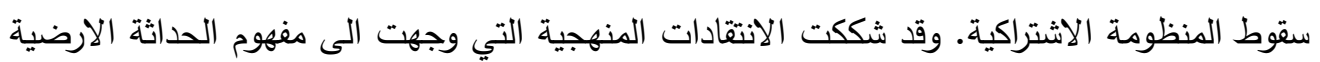
العلمية التي تتامى في ترتيبها مفهوم ما بعد الحداثة ليأخذ صورته النقدية التي تغذيها روح فكرية نقدية نشطة ومتطورة وقد لا نبالغ اذا قلنا بأن هذه الانتقادات التي تتامت في حقل الحداثة شكلت ايضا نبوغا للتنظير العلمي المتقدم والابداعي في ميدان ما بعد الحداثة وتأسيسا على ذلك يمكن القول بأن مفهوم ما بعد الحداثة لا يأخذ اهميته بوصفه امتدادا زمنيا لحالات حضارية متعاقبة بل هو نسق من التصورات النقدية التي ابدعتها روح العصر المتجدد في مختلف ميادين الحياة الفكرية وفي غمرة 
المؤتمر العلمي الاولي الحادي عشر

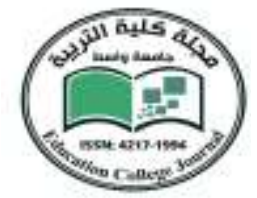

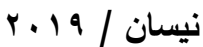

جامعة واسط

مجلــــة كليــــة التربيــــة

الانتقادات التي وجهت الى الحداثة وفي ملامح الازمة التي تعيشها الحداثة دفعت بعض الباحثين الى الاعتقاد بأن الانسانية خرجت تحت تأثير هذه الاختناقات الحضارية من مرحلة الحداثة وبدأت مرحلة

جديدة اطلق عليها ما بعد الحداثة (TV).

أن نقد الحداثة يقدم نقطة انطلاق هامة للخطة ما بعد الحداثة للمضي اشواطا بعيدة في تجذير هذا النقد وتعقيمه ، أذ لا يجري نقد الحداثة فقط بل نفيها وتدميرها ، ومن ثم يذهب ايهاب حسن الى ان لحظة ما بعد الحداثة تمثل نوعا من الانفجار الذي سوف يؤدي بالحداثة وبعقلانيتها وموضوعاتها الى التشتت الى وحدات وقطع ولهذا يظهر مفهوم ما بعد الحداثة كنشر في الاسس وكسر للقوالب وخروج على النماذج ، بل ان ثمة تفجيرا للاشكال وتدميرا للانساق على نحو خارق مدهش وخروجا عن خط الضرورة التاريخية في صورة طرح جديد يعتقد جياني فاتيمو بانه تم في شكل الحدوث. وقد كان من اهم دوافع ظهور فلسفة ما بعد الحداثة اعادة الاعتبار لما هو "ميتافيزيقي " ليس بمنظور الفكر القديم اي باعتباره يحمل مضامين " عالما مجهولا " تسعى الفلسفة الى اكتشاف افاقه ، وانما باعتباره يحمل مضامين لفكر الانسانية برمتها ، اي البحث في محاولة تتديب " العقل المادي " الذي اطلقته قوى

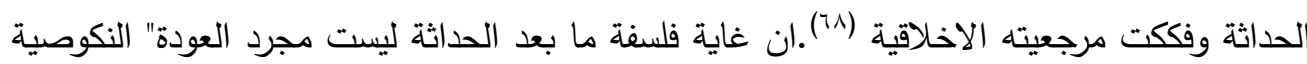
" بالفكر الانساني الى حالته البدائية من حيث القدرة على التنكير واكتثاف المجهول بقدر ما هي تحديد الاطار الاخلاقي والانساني لهذا العقل اي اعادة الصفة المعيارية له وضبط بوصلته الانسانية اي انها ترشيد " الترشيد " الحداثي ، او بالاحرى ضبط " حركة " العقل الحداثي واعادته الى حظيرة الاخلاق والقيم الانسانية او بالاحرى وعلى نحو ما يشير جان فرانسوا ليوكار فيلسوف ما بعد الحداثة انها ايعاز اللجوء الى الضمير كمدر للفعل الانساني " وليس فقط العقل كمصدر وحيد له وذلك على نحو ما تتادي به فلسفة الحداثة (19). كما ان ما بعد الحداثة نظرت الى الدين بعكس ما نظرت اليه الحداثة ، أذ يعد الدين احد الاطر او الاعمدة التي تسعى فلسفة ما بعد الحداثة الى التركيز عليها باعتبارها احد اشكال الضمير الانساني ، واعادة النظر للدين من قبل ما بعد الحداثة ليس بصفته مجموعة من النصوص والقيم اللانعوتية وانما باعتباره " سياجا " روحيا يضع الخلفية الانسانية لحركة العقل في تحليله الظواهر الاجتماعية وتعاطيه مع الواقع السياسي المعقدة ، وهذا الاهتمام ما بعد 
المؤتمر العلمي الاولي الحادي عثر

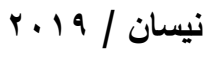

جامعة واسط

مجلــــة كليـــة التربيـــة

الحداثي للدين لا ينطلق من الحاجة الى تتييد العقل عبر طقوس وشعائر بعينها فهذا هو التدين وليس الدين ، وانما فقط محاولة لاعادة الاعتبار لمصادر الضبط الذاتي سواء كانت دينية ام ما وراثية ام اخلاقية ونقد ما بعد الحداثة للحداثة لا يعني التخلي المطلق عن منتحات الحداثة او هدم منظومة للافكار والمناهج التي طورتها هذه الفلسفة خلال القرنيين الماضيين بقدر ما يعني الاستجابة لحال

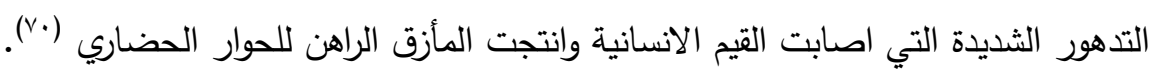
ولهذا رأى بعض الباحثين ان فكر ما بعد الحداثة ليس الا شقا ضمن الحداثة او هو ذلك الجانب

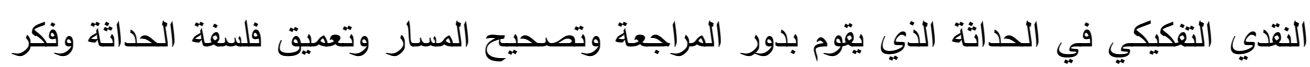

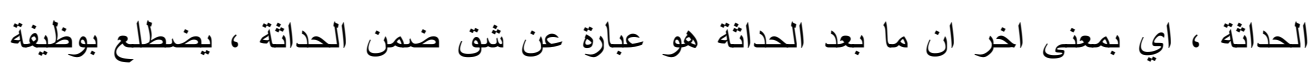

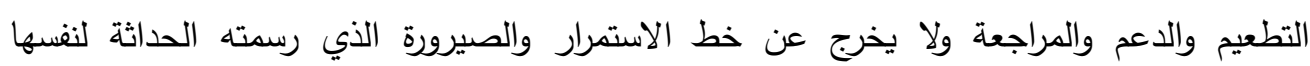
باعتبارها مفهوما غير قابل للاستنفاد ، ولهذا اطلقوا على هذه المرحلة اسم الحداثة البعدية " التي

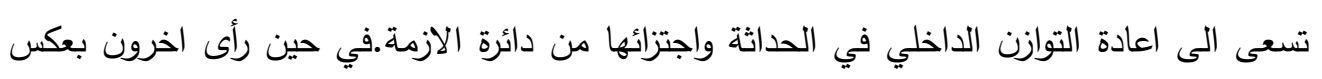

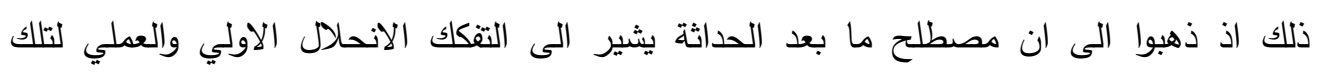
الاشكال الاجتماعية التي ارتبطت بالحداثة ولذلك يوصف بكونه مصطلح نفي سلبي لانه نفي كل ما جاءت به الحداثة ولم يوفر البديل.

\section{المفهوم والدلالة :}

ان ايجاد تعريف جامع وشامل لكفهوم ما بعد الحداثة امر شائك ، أذ لم النقاد تحديد سمات وقواعد يتبعونها في تصنيف نوع فني او اخر وادرالك يقوم على اساس تقويض كل ما قبله اضافة الى انه لا يملك فن جوهر اي رغبة في تحديد قوانين او ادرالك كنه او جوهر الفن بل على العكس هو تيار يهدف بالدرجة الاولى الى التثكيك بكل شيء.

وقد اشار ايهاب حسن احد المنظرين في مجال ما بعد الحداثة الى صعوبة تحديد هذا الففهوم ، ولكنه مع ذلك يقدم مجموعة من التصورات القا التي يمكنها ان تثكل العناصر الاساسية في بنية المفهوم ومنها : ان لفظ ما بعد الحداثة يوحي بفكرة الحداثة وهو بالتالي يتضمن التوالي الزمني 
المؤتمر العلمي الاولي الحادي عشر

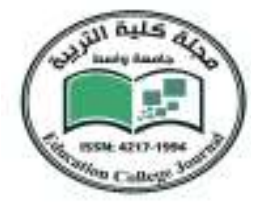

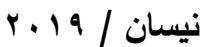

\section{جامعة واسط}

مجلــــة كليـــة التربيـــة

للعلاقة بين المفهومين ('الا يوجد اجماع بين النقاد على تعريف واضح لمفهوم ما بعد الحداثة.مفهوم ما بعد الحداثة عرضة كغيره للتعبير والصيرورة التي نلاحظها في المفاهيم الوليدة حديثا.ومن هذا المنطلق يمكن الاشارة الى موقف يورجين هابرماس من هذا المفهوم في مقالته " الحداثة مشروع لم يكتمل " الذي نشره في عام ، حيث يرى بأن لفظة ما بعد الحداثة تمثل رغبة بعض المفكرين الابتعاد عن ماض متشبع بتتاقضات كبيرة وتعبر في الوقت نفسه عن سعي حثيث الى وصف العصر الجديد بمفهوم لم تتحدد ملامحه بعد ذلك لان الانسانية لم تستطع ان تجد الحلول المناسبة للاشكاليات التي يطرحها العصر ، وفقا لهذه الصيغة يرى هابرماس بأن ما بعد الحداثة هي صيغة جديدة لمفهوم قديم " الحداثة " وان ما بعد الحداثة محاولة لاثراء الحداثة ذاتها واتمام مشروعها حتى النهاية وعلى الرغم من صعوبة تحديد هذا المصطلح في تعريف جامع وشامل . كما وان بعض المفكرين والنقاد حاولوا اعطاء تعريف اشبه ما يكون بالمفهوم الذي يقرب فكرة ما بعد الحداثة ، حيث عرفها بعضهم على انها " مجموع الظروف والثروط المختلفة والمتعددة التي تختلط فيها المظاهر الاجتماعية بالمظاهر الاجتماعية الثقافية فلا يمكن التمييز بين ما هو اجتماعي وما هو ثقافي ، فتتهار المسافة بين النظرية وموضوعها ، ويتغير الفصل بين النظرية التأويلية والواقع الاجتماعي الذي تحاول النظرية ادراكه وتوصيفه "(VT) ، ولهذا يرى منظرو ما بعد الحداثة ان جزءا كبيرا من مفهوم ما بعد الحداثة يعتمد على صعوبة الفصل بين البنية المعرفية وبين ما تتتجه هذه البنية من معرفة ، اذ ان هناك تداخلا مستمرا بين اشكال المعرفة وبين ما تسعى الى دراسته.

اما ماك غرايت فانه يعرف ما بعد الحداثة بانها الالتزام المسبق بالنسبية والتعددية فيما يخص قضايا الحقيقة واحدى المجالات التي تلقى الشعبية في فكر ما بعد الحداثة هي التأكيد على ان كل فرد هو جزء من مجتمع انساني محلي ، ولذلك لا بد من تفسير الحقيقة على ضوء ذلك المجتمع ، ولان هناك الكثير من المجتمعات المحلية المختلفة تعتقد ما بعد الحداثة ان هناك الكثير من الحقائق المختلفة التي يمكن ان تتوحد مع بعضها.. فطالما كانت الحقائق مرتبطة بالبيئة الاجتماعية التي تظهر فيها فان ما يكون صحيحا لدى البعض قد لا يكون كذلك لدى من يعيشون لدى بيئة اجتماعية اخرى 
المؤتمر العلمي الاولي الحادي عثر

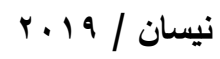

جامعة واسط

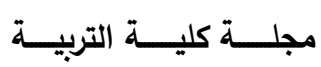

ما بعد الحداثية... وما بعد الحداثة :

يفرق بعض الباحثين بين مصطلح ما بعد الحداثة وما بعد الحداثية او ما بعد الحداثي ، فاذا كان

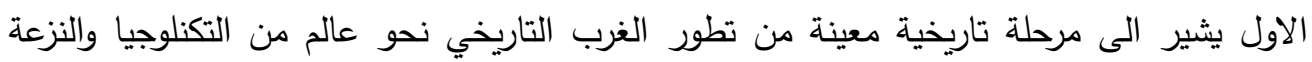

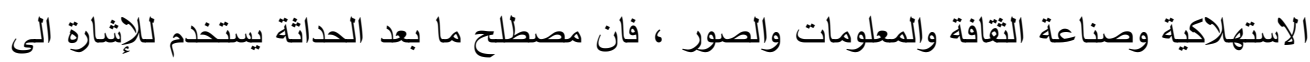
شكل من اشكال الثقافة المعاصرة التي يعكس اسلوبها شيئا من التغيير التاريخي الذي يذوب الحدود

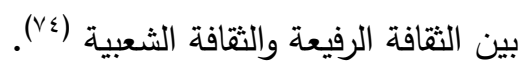

\section{مراحل تطور مصطلح ما بعد الحداثة :}

ان تتبع ظاهرة ما بعد الحداثة في الثقافة الغربية عند الباحثين الذين يتبعون تاريخ الافكار في الثقافة الغربية تتلخص بثلاث مراحل هي : بن

المرحلة الاولى : التي يمثلها التطور الديني الذي برزت فيه فكرة العناية الفوقية بوصفها طريقة في

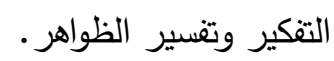

المرحلة الثانية : يمثلها طور العلم والتتوير الذي كانت الغلبة فيه لفكر التقدم وللنزعة الانسانية القائمة على الثقة في قدرات الانسان.

المرحلة الثالثة : يمثلها طور الانزلاق الى العدمية التي ترى الكون لعبا بحظ ولا ينضبط بغاية او هدف او قانون كلي ، أذ برزت في الصد فكرة النسبية المطلقة.

واذا كان المصطلح يدل الى مرحلة تاريخية معينة من تطور الغرب التاريخي نحو عالم من

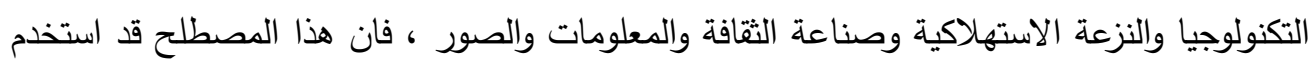
من قبل توبيني للإثارة الى التغييرات التي شهدتها الحضارة الغربية في نهاية القرن التاسع عشر ، اما

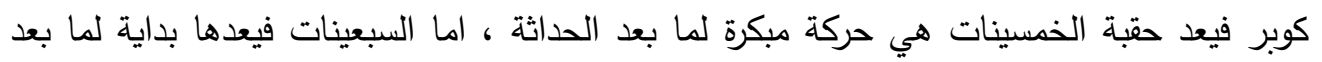

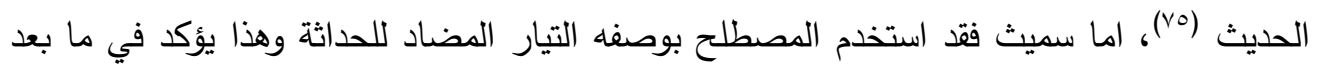
الحداثة على نفي الذات الفردية البرجوازية نفيا منظوميا لفهم الحداثة نفسها للإنسان او الفرد بوصفه قيمة بحد ذاته او القيمة الاساسية التي ترتد اليها كل القيم. وهي لذلك اسلوب في الفكر يبدي ارتيابا 
المؤتمر العلمي الاولي الحادي عثر

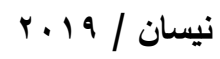

جامعة واسط

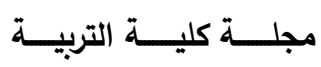

بالأفكار والتصورات الكلاسيكية لفكرة الحقيقة والعقل والهوية والموضوعية ، والتقدم ، او الانفاق الكوني والاطر الاحادية والسرديات الكبرى ، ومع بداية الثمانينات اخذ مفهوم ما بعد الحداثة يستخدم

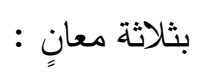

1. للإثشارة الى المرحلة الثقافية التي نعيشها والتي تعصف بتعبيرات قيادية.

r. بوصفها جمالية تمزق فرضيات تسليح الثقافة من خلال تثثلها ما يسمى بسياسات الرغبة.

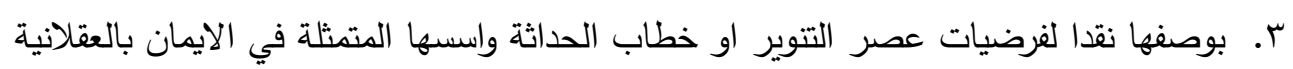

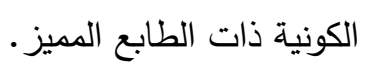

ما بعد الحداثة ... ما بعد البنيوية :

اصبح مشروع ما بعد الحداثة منذ السبعينات يتطابق مع مشروع ما بعد البنيوية الفرنسية من

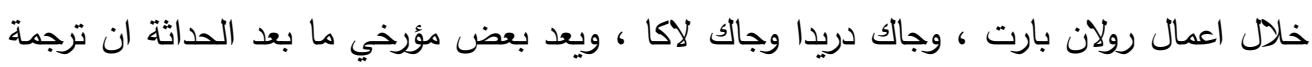

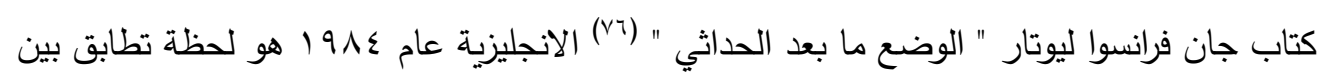
المشروعين ما بعد الحداثي وما بعد البنيوي ، ويشير ويندل. ف هاريس الى ان هناك لـان كتابا يميلون

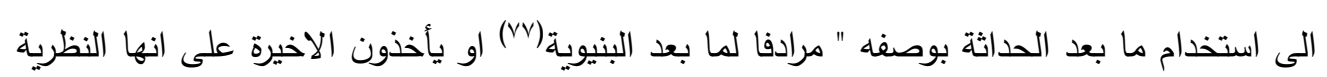

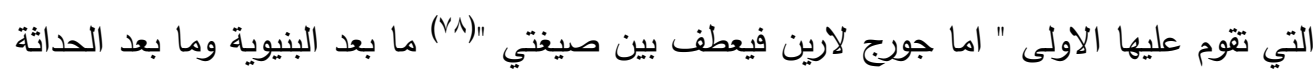

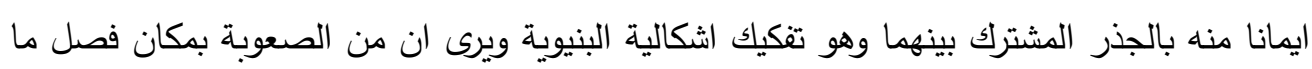

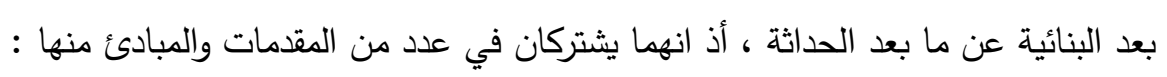

$$
\text { r. r. . تركيز الخطاب على الحياة الاجتماعية. }
$$

ان استخدام ما بعد الحداثة لهصطلحات تعود الى ما بعد البنائية مثل التفكيك والارجاء ومصطلحات جديدة اللغة الطفيلية والعقلية الجدلية المنطقية والتركيبة الاجتماعية والميتا حكاية والميتا لغة وما اليها لهاء فضلا عن استعارة معظم النقاد من اصحاب النظريات بعض الافكار من نظرية التفكيك باستعمالها 
المؤتمر العلمي الاولي الحادي عثر

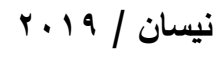

جامعة واسط

مجلــــة كليــــة التربيــــة

في نظرياتهم عن ما بعد الحداثة كل هذا يؤكد ارتباطهما على المستوى الفكري النظري ، بل وان العديد من منظري التفكيكية هم منظرون لما بعد الحداثة. وقد تجلى هذا التطابق برفض منظري المشروع ما بعد الحداثي تصور الفلسفة التجريبية للغة، الذي يقول ان اللغة تمثل الواقع منطلقين من ان اللغة لا تعكس العالم " الواقع " بل تقوم بتأليفه.

فالسمة الجوهرية لمفهوم ما بعد الحداثة للنص هي سمة نصية او سمة في الكتابة تؤنس في الفضاء ما بعد البنيوي على مفهوم الاختلاف لدى دي سويسر الذي يرى ان المعنى في اللغة هو مجرد اختلاف بين العلاقات اللغوية التي يتألف كل منها من وحدة دال ومدلول ويأتي دريد البعض هذه الوحدة ويفصل ما بين الدال والمدلول...

وهذا يعني ان الطرح النقدي الثامل لما بعد البنيوية قد شكّل المادة التي انتفعت منها ما بعد الحداثة من خلال ظواهره الخطابية.

\section{ما بعد الحداثة " الاستراتيجية " المنهج " السمات والمعالم :}

تشمل استراتيجية ما بعد الحداثة ومنهجيتها وطروحاتها الفكرية والفلسفية فيما يلي :

ا. . المنظور التاريخي الذي يعد حركة ابتعاد عن الحداثة او رفضا لبعض جوانبها.

r. المنظور الفلسفي أذ انها تقوم على الفراغ الذي اوجده غياب وتقويض الحداثة وذلك التقويض الذي استخدم المفاهيم ما بعد البنيوية في الغاء محدودية المعنى وامكانية تقريره وتأكيد ان الحقيقة

$$
\text { الثابتة ما هي الا صناعة لغوية. }
$$

". المنظور الايديولوجي السياسي " منظور التحيز " أذ ان اهمية ما بعد الحداثة تكمن من خلال نتائجها ، أذ هي قادرة على خلق الاشكاليات ضمن المسلمات حتى يتسنى لها خلخلة الثقة بما لم يكن سابقا يقبل الثك وبذلك تلعب ما بعد الحداثة دورا مهما في اعادة تعريف الحقائق المتغيرة وفي زعزعة الثقة بالثوابت مما يفضي الى تعرية صيرورة الحقائق 
المؤتمر العلمي الاولي الحادي عشر

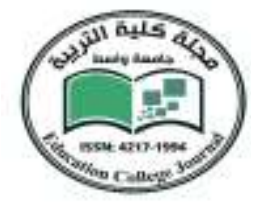

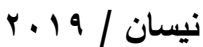

\section{جامعة واسط}

مجلـــة كليـــة التربيـــة

ء. المنطق الاستراتيجي النصوص أذ تسعى ما بعد الحداثة الى تأصيل النص وانفتاحه وانكاره للحد

والحدود ، مما يجعله يقبل التأويل المستمر والتأطير المتحول ابدا ، وينجم عن هذه النصوصية

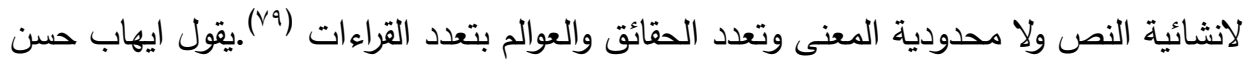

: ان سمات ما بعد الحداثة هي اللا توجه التي تساعد هذه الدفاهيم على تقلبها وتدويرها :

الالتباس " الانقطاع " هرطقة الخروج على المألوف...التعددية العشوائية " التمرد " الثذوذ " التحويل التثويهي والمفهوم الاخير يدل وحده على مجموعة من المصطلحات الواهنة حول

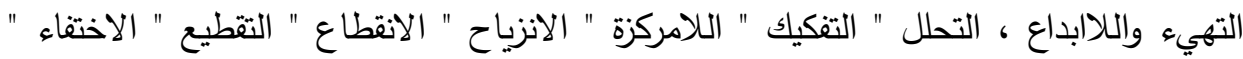
الانحلال " اللاتعريف " اللاكليانيه ، اللاشرعنه.. هذا اذا وضعنا جانبا مصطلحات تقنية اخرى تثير الى بلاغة المفارقة والثرح والصمت وفي القرار من جميع هذه العلامات تتحرك ارادة واسعة باتجاه التهديم فتؤثر على كتلة السياسة وكتلة المعرفة والباطن النفسي والفردي اي كامل الكون الخطابي في المغرب (·^).يرى سكوت ليش ظاهرة ما بعد الحداثة بوصفها حدثا ثقافيا وتميلك ثلاث مواصفات عامة فهي اولا نتاج سيرورة التمايزات الثقافية، وهي ثانيا خلق لنظام جديد من الرموز المجتمعية المتصفة بالرؤيوية اكثر من اتصافها بالملموسية، وثالثا هي ظاهرة تعكس تغيرات واضحة وجلية في التصنيف والتراتب الاجتماعيين.اذا كانت الحداثة تعني العقلانية المادية التي اثمرت الاستارة المضيئة التي منحت الانسان المركزية والمكانة الخاصة التي ميزته عن الكائنات الاخرى فان ما بعد الحداثة قامت على رفض فلسفة التنوير العقلاني وعلى ان الحقيقة ليست ثمرة معرفة موضوعية، بل هي علاقة قوة ، تسعى الى تفكك الذات الانسانية وان الحديث عنها بوصفها مبدعة حرة مستقلة وهم من اوهام الفكر الانساني.تسعى ثقافة ما بعد الحداثة الى ترسيخ وجودها عبر تحطيم او نقض الثقافة الحداثية ، فاذا كانت الحداثة امعنت في تشويه وادانة الثقافة الجماهيرية لأمور الثقافة، إذ الثقافة العليا والثقافة الثعبية فأن ما بعد الحداثة سعت الى تعدد اشكال التعبير الثقافي ، كما انها تسعى الى تحويل مشروع المعرفة الى مشروع رمزي لغوي استعاري غير تتظيري اي باختصار الى مجرد عمل فردي. 
المؤتمر العلمي الاولي الحادي عشر

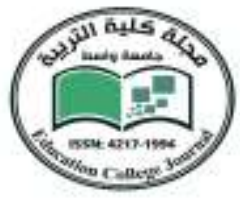

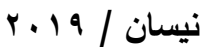

\section{جامعة واسط}

مجلـــة كليـــة التربيـــة

ان المجتمع ما بعد الحداثي يبدو أثبه لمجتمع الخدمة الذاتية والاغراء فيه بمثابة مسار شامل ينزع الى تنظيم الاستهلاك والمنظمات ، والاعلام والتربية والاخلاق ، وهكذا جاءت علاقات الاغراء بديلاً عن علاقات الانتاج ، انه يتجه نحو الحد من العلاقات السلطوية والاثارة في الخيارات الخاصة، وفي منح الأولوية الى التعددية والازدراء بالقيم الكبرى وبالغائيات التي تتظم العلاقات في الاسرة والعمل والجيش، وتتم السلبية بوصفها القيمة الوحيدة التي يسعى الجميع لتحقيقها مما ينتقي بالمجتمع الى حالة من التذرر والقلق والتثاؤم.

حاول بعض النقاد رصد بعض السمات لما بعد الحداثة في الفنون وأهمها المفارقة، والتعددية الساخرة، والحنين الى الماضي أو استثارة ذكريات معينة، واستخدام قصص رمزية غامضة المعنى (1). يرى بعضهم انه يجب قراءة الفكر ما بعد الحداثي كانعكاس لما يحصل من تحولات اجتماعية واقتصادية ونفسية في المجتمعات الغربية، وهم بذلك يعودون بظاهرة ما بعد الحداثين الى نقطتين رئيسيتين:- اولاهما التأكيد على خصوصية الظاهرة بحكم نشأتها في المجتمعات الغربية، وعدم خضوع المجتمعات الاخرى لتحولات من نوع مماثل مما يجنبها او يبعدها عن الجدل الدائر حول ما بعد الدداثة، اما النقطة الاخرى فهي الاصرار على الربط الميكانيكي بين الفكر ما بعد الحداثي

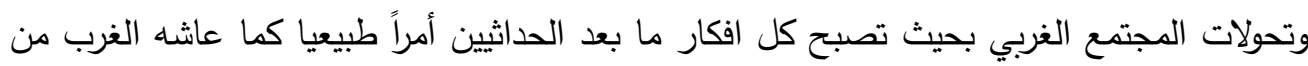
تاقص في الايديولوجيا الحداثية، لا سيما في علاقات المركز بالهامش وما نشأ عنها على علاقات الاستغلال، وفقدان للمساواة وسيطرة للنخبة وفرض هيمنة التغريب على مجتمعات العالم الثالث (r^ه). ليس هناك ما بعد حداثة واحدة بل هناك ما بعد حداثات، لكنها تشترك جميعا في بعض الانس النظرية وصلات النسب بأفكار عدد من ملهمي الفكر الغربي المعاصر في نهاية القرن العشرين فهناك ما بعد الحداثة في الفنون وما بعد البنيوية في الفلسفة ، والنسوية في الخطاب الاجتماعي ، ودراسات ما بعد الاستعمار، والدراسات الثقافية في الاكاديمية ، وكذلك تضم الرأسمالية العالمية ، وتكنولوجيا الاتصالات والارهاب الدولي ، والاختلاف العرقي والقومي والحركات الدينية ، كل هذه الظواهر تقع في سياق ما بعد الحداثة دون ان يكون متضمنة فيها بشكل سببي، فضلا عن ذلك فان 
المؤتمر العلمي الاولي الحادي عثر

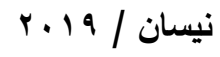

جامعة واسط

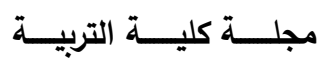

ما بعد الحداثة قد دخلت في مجالات كثيرة جدا في خطاب الهندسة المعمارية والفنون المختلفة والعلوم الانسانية والفيزياء والخطاب الاكاديمي والثعبي وعوالم السياسية ، والبيزنس والميديا وصناعات التسلية ، كذلك شاعت في الاساليب الشخصية للحياة ، مثل طريقة طهو ما بعد حداثية ومطبخ ما بعد حداثي.يرى ايهاب حسن ان ما بعد الحداثة تتواءم كظاهرة ثقافية مع الثقافية العالية ، والمستهلك وقيادة الاجهزة الاعلامية الاجتماعية ، ثم انها كعملية جغرافية سياسية عالمية تشير الى ظاهرة كوكبية تفاعلية يتخلل نسيجها القبلية والامبريالية والاساطير والتكنولوجيا والهوامش.

\section{الهوامش:}

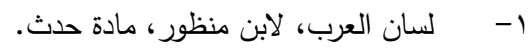

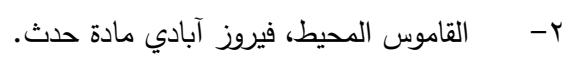

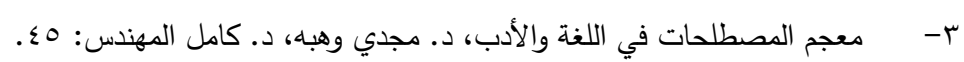

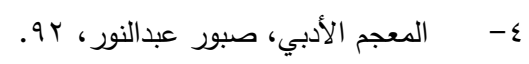

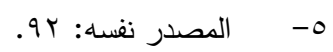

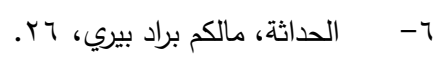

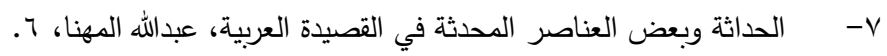

- م- المصدر نفسه: 7.

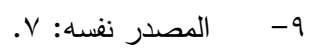

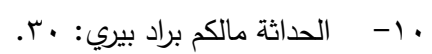

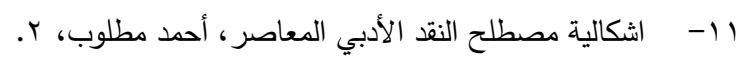

r إ- الحداثة وبعض العناصر المحدثة: 7.

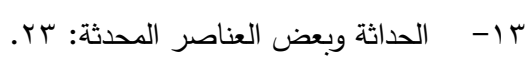

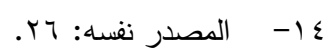

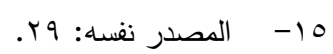

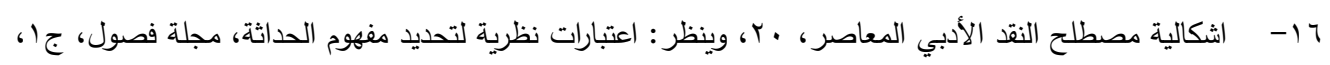

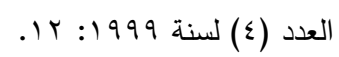

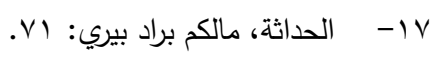




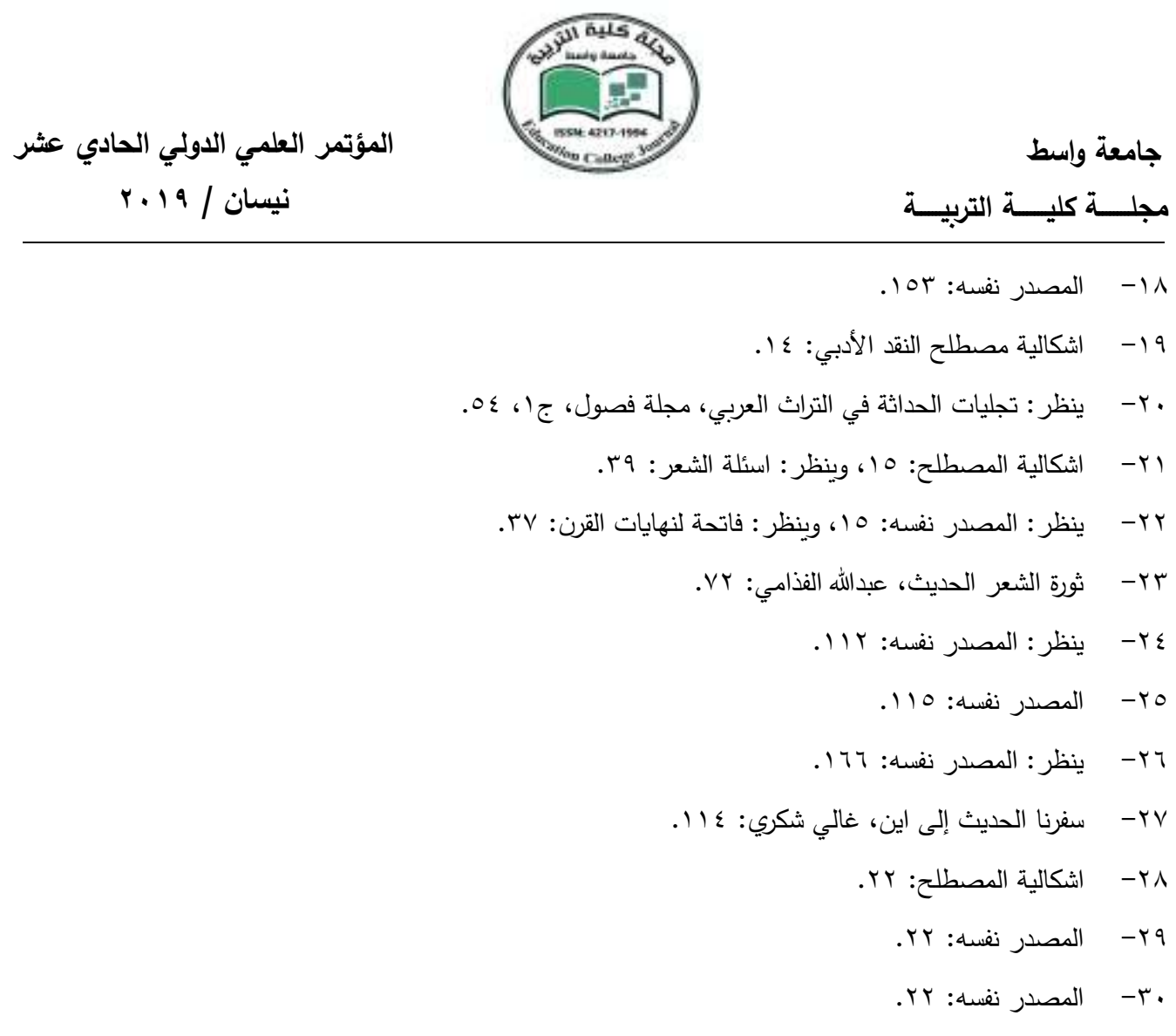

اب- الحداثة وبعض العناصر المحدثة في القصيدة العربية، عبدالله المهنا: 11. ץr- النقد والحداثة، عبدالسلام المسري: ^.

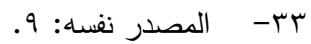
צ 9

هب- الحداثة في الشعر العربي المعاصر، محم العبد حمود: ror. דب- الحداثة وبعض العناصر المحدثة للقصيدة العربية المعاصرة عبدالله المهنا: 1 |-9 |.

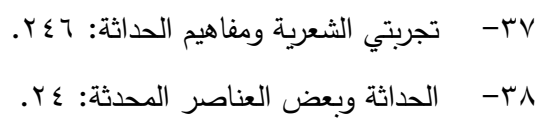
q ب- المصدر نفسه: 0ب، وينظر : ادونيس زمن الشعر، علي احمد سعيد: 9.

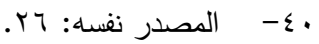

اء- الحداثة وبعض العناصر المحدثة: جr، وينظر : ادونيس زمن الشعر : 10. r

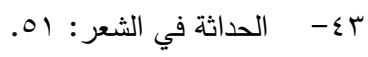
ع 


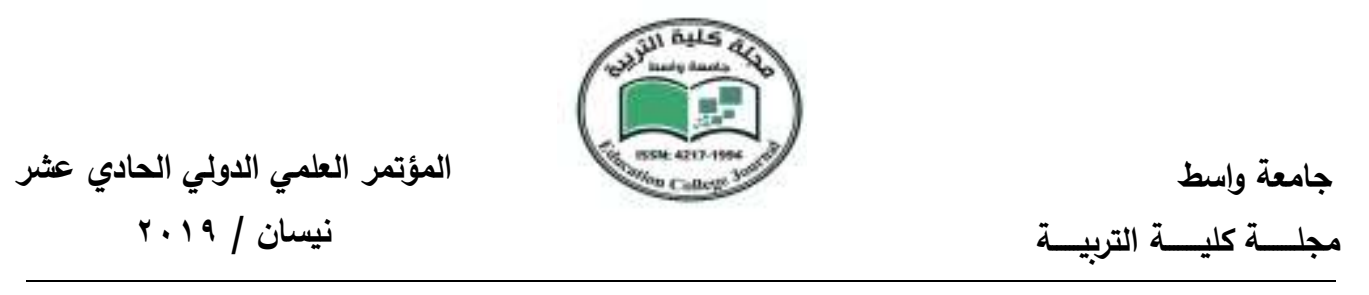

0ـ- ينظر : الحداثة والبنيوية في معرفة النص الأدبي، د. جودت الركابي: ع ا.

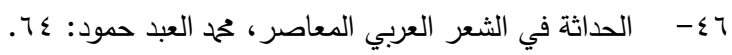

. 10 - المصدر نفسها:

ــ - النقد والحداثة، عبدالسلام المسدي: ـ 1.

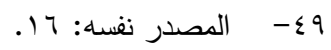

. - - افق الحداثة وحداثة النمط، سامي مهدي، 1؟ ا.

10- المصدر نفسه: 1؟ ا.

ror - الحداثة في الشعر العربي المعاصر، محمد العبد حمود: 17.

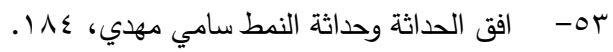

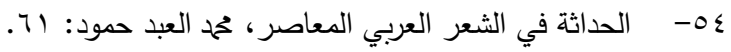

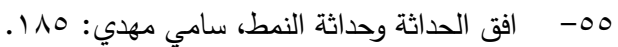

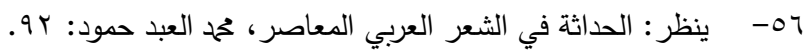

- T

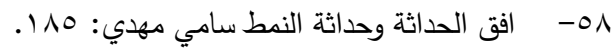

9- الحداثة وبعض العناصر المحدثة في القصيدة العربية، عبدالله المهنا: بr.

. T- المصدر نفسه: بr.

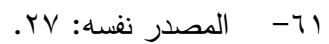

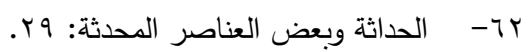

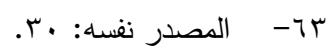

ع ؟- ينظر: دليل الناقد الأدبي، ميجان الدوبلي وسعد الباربحي: 10.

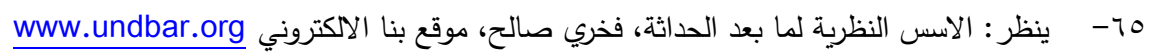

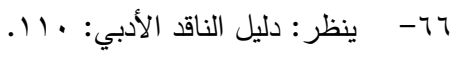

V V- ينظر : الحداثة وما بعد الحداثة، تثبيت الأصول ام كسر النماذج سعد المتدين، موقع النبأ.

1 1- المصدر نفسه.

79- ينظر : مصطلحات أدبية، الحداثة وما بعد الحداثة، موقع بنأ.

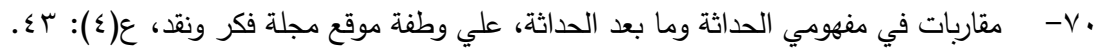

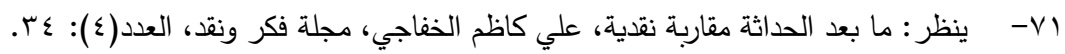




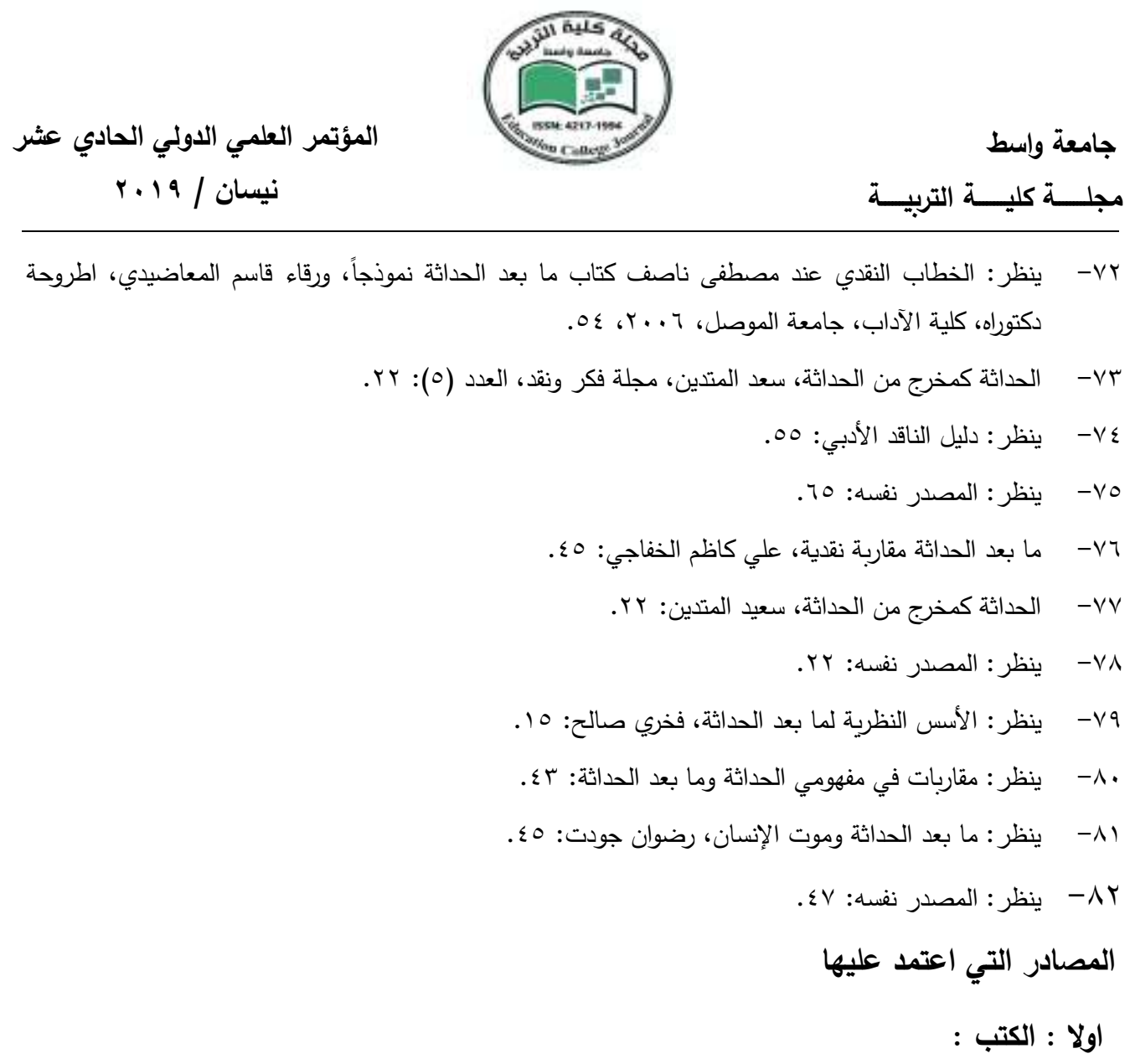

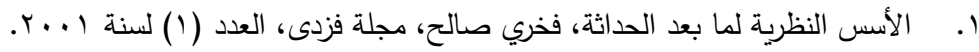

r. الحداثة في الشعر العربي المعاصر، محم العبد حمود، 999 1، الشركة العالمية للكتاب.

r. تجربتي الثعرية ومفاهيم الحداثة، المجلس الوطني للثقافة والفنون والآداب، 1911 .

ع. الحداثة كمخرج من الحداثة، سعيد المتدين، دار الثارقة، الطبعة الأولى، ؟ ... .

ه. الحداثة مالكوم براد بيري، ترجمة وتحقيق: مؤيد حسن فوزي، الطبعة الأولى، دار المحبة، 9 . . ؟.

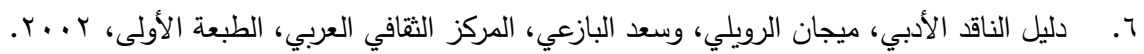

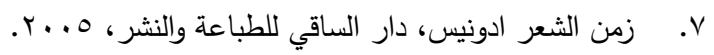

^. سفرنا الحديث إلى أين، غالي شكري، دار المعارف، الطبعة الأولى، 1991.

9. في معرفة النص الأدبي، جودت الركابي، دار المعارف، مصر ، الطبعة الأولى، ل ...

• ا. القاموس المحيط، لفيروز آبادي، المحقق نعيم العرقسوسي، الهيئة المصرية العامة للكتاب .919 ام. 11. لسان العرب: ابن منظور ، دار احياء التراث العربي، بيروت، 1999. 


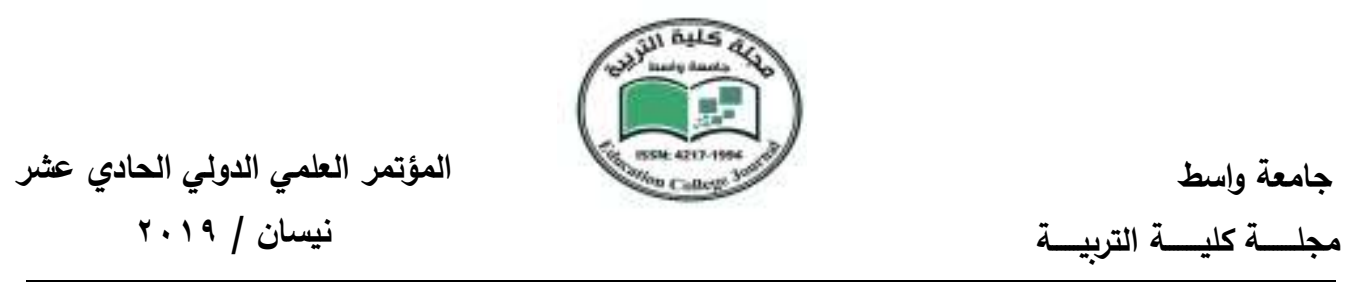

r ا. معجم المصطلحات في اللغة والادب، مجدي وهبه، كامل المهندس.

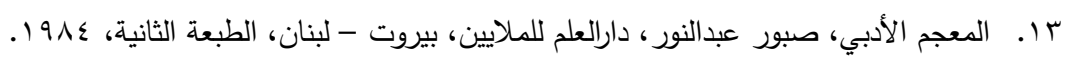

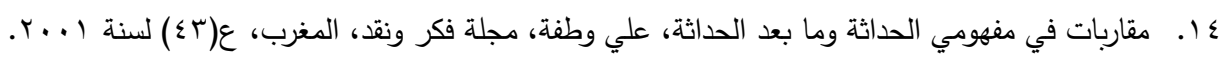

10

ثانيا : الرسائل الجامعية :

الخطاب النقدي عند مصطفى ناصف كتاب " بعد الحداثة " انموذجا ، ورقاء يحيى قاسم حياوي المعاضيدي ، اطروحة دكتوراه ، كلية الآداب جامعة الموصل ، 7 . - זم.

ثالثاً: الدوريات:

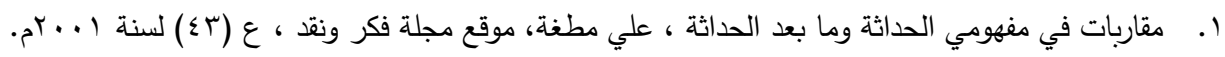

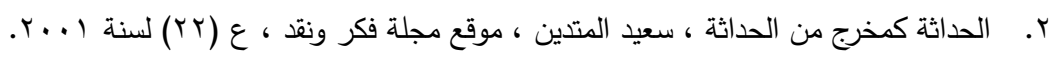

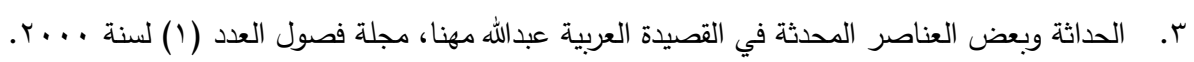

ع. اشكالية مصطلح النقد الأدبي المعاصر ، أحمد مطلوب، مجلة فصول العدد (1) لسنة ... . ب.

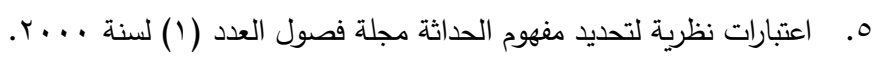

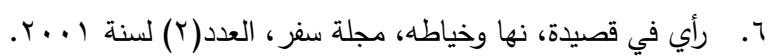

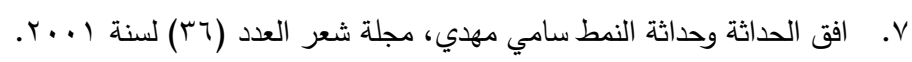

^. الحداثة وما بعد الحداثة - تثبيت الأصول ام كسر النماذج، سعيد المتدين، مجلة الكرمل رام الله العدد (10)

$.199 \mathrm{~V}$

رابعاً : الانترنيت:

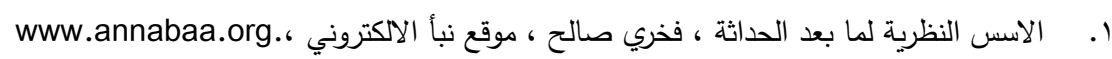

الحداثة وما بعد الحداثة كتيب الاصول ام كسر النماذج ، سعيد المتدين ، موقع نبأ 